\title{
Instituciones y gobierno extraordinario. Flandes en tiempos del Grand Condé (1651-1659)
}

\author{
Institutions and extraordinary government. The Habsburg Netherlands in the time of the Grand \\ Condé (1651-1659)
}

\section{Lourdes Amigo Vázquez ${ }^{1}$}

Universidad de Valladolid

Resumen: Luis II de Borbón-Condé irrumpió en la política de Flandes a finales de 1651, por su alianza con Felipe IV, en el marco de la guerra Franco-Española y de la Fronda. Es más, su exilio en aquellas provincias se hizo ya inevitable, en el verano de 1653. Esta coyuntura, que se prolongó hasta la Paz de los Pirineos, conllevaría importantes alteraciones en el gobierno general de Flandes, hasta el punto que podemos calificarlo de "extraordinario". El héroe de Rocroi, amparado en su dignidad y prestigio y en el apoyo inquebrantable del rey católico y de su propia clientela, siempre defendió el estatus y poder que consideraba corresponderle. Así, a la autoridad de las principales instituciones y ministros de Felipe IV en los Países Bajos católicos se añadió y, en muchas ocasiones, se opuso la del Grand Condé.

Palabras clave: Luis II de Borbón-Condé; Monarquía Hispánica; Flandes; Francia; Siglo XVII; instituciones; política; gobierno; ejército; exilios.

\begin{abstract}
Louis II of Bourbon-Condé burst into the politics of the Habsburg Netherlands at the end of 1651, as a result of his alliance with Philip IV. He played a key role in both the Fronde and the Franco-Spanish war. His exile in the Spanish Netherlands became inevitable from the summer of 1653 . He remained there until the Peace of the Pyrenees (1659). This extraordinary situation provoked enormous instability in the government of the Spanish Netherlands. The hero of Rocroi consistently defended his status and power, which he based upon his prestige and
\end{abstract}

\footnotetext{
${ }^{1}$ http://orcid.org/0000-0001-7906-9067

Este trabajo ha sido realizado en el marco de los siguientes proyectos: Hispanofilia III: la influencia ibérica en su contexto político, siglos XVI-XX, Código HAR2014-52414-C2-1-P, del MINECO, y Columnaria I. Comprender las dinámicas de los Mundos Ibéricos, Código 19247/PI/14, de la Fundación Séneca (Región de Murcia).
}

(C) 2018 Philostrato. Revista de Historia y Arte 
standing in France, the unwavering support of the Catholic King and the steadfast loyalty of his own clientele networks. In this way the figure of the Grand Condé loomed over - and often challenged - the leading institutions and ministers of Philip IV in the Southern Netherlands.

Key Words: Louis II of Bourbon-Condé; Spanish Monarchy; Habsburg Netherlands; France; Seventeenth Century; institutions; politics; government; army; exiles.

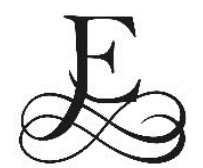

n septiembre de 1654, Jerónimo de Barrionuevo escribía, sobre los rumores que circulaban en Madrid acerca de la situación en Flandes:

"Dícese por acá no es acertado hacer la guerra con tantas cabezas y generales, que envía [su majestad] a llamar a Fuensaldaña, que el archiduque no salga de los Estados y que el Príncipe de Condé gobierne solo las armas, como lo hizo [el condestable de] Borbón en tiempos de Carlos V"2.

Aunque lo planteado por Barrionuevo nunca llegó a producirse, tampoco estaba muy alejado de la realidad, como podremos comprobar. De uno de estos personajes, si bien en un tono alarmista que, por otra parte, no fue lo común en la corte madrileña, opinaba el marqués de Valparaíso, en la reunión del Consejo de Estado, el 25 de noviembre de ese mismo año. Consideraba "que el Príncipe de Condé ha tomado y toma tanta authoridad y mano en Flandes, que por esto, su actividad y viveza, se puede temer la perdición de aquellos países, y que tiene esta por materia tan grande que conviene no perderla de vista y remediarla"3.

Luis II de Borbón, conocido como el Grand Condé, había irrumpido en la política de Flandes a finales de 1651, por su alianza con Felipe IV, en el marco de la guerra Franco-Española y de la Fronda. Un año después, el 13 de octubre, el que era el primer príncipe de sangre francés, entonces "malcontento" de Luis XIV, abandonaba París y se dirigía a la Champagne. Aquí comenzó a gestarse su exilio en los Países Bajos meridionales, ya inevitable unos meses después, como consecuencia de los fracasos de la campaña militar de 1653, cuando perdió la mayoría de sus plazas en el norte de Francia, y, muy especialmente, cayó Burdeos, en julio, marcando el fin de la Fronda. Esta coyuntura, que se prolongó hasta la Paz de los Pirineos, conllevaría importantes alteraciones en el gobierno general de Flandes, hasta el punto que podemos calificarlo de "extraordinario"4.

\footnotetext{
2 Jerónimo de Barrionuevo, Avisos, vol. 1 (Madrid: Imprenta y Fundición de M. Tello, 1892), p. 69 (30-IX-1654).

${ }^{3}$ Archivo General de Simancas (AGS), Estado, leg. 2083, exp. 142, Consejo de Estado, 25-XI1654.

${ }^{4}$ En las biografías francesas todavía pesa la imagen del héroe, creada en tiempos del Grand Condé y alimentada por los trabajos eruditos del siglo XIX, muy particularmente por Duc
} 
El héroe de Rocroi, amparado en su dignidad y prestigio y en el apoyo inquebrantable del rey católico y de su propia clientela, siempre defendió el estatus y el poder que consideraba corresponderle. De esta forma, a la autoridad de las principales instituciones y ministros de Felipe IV en Flandes, se añadió y, en muchas ocasiones, se opuso la del Grand Condé. Actuó, en definitiva, sobre todo a partir de 1653 , como una "autoridad informal"5, que entró en competencia con la cúspide del poder oficial, integrado, a nivel institucional, por el Gobernador General y el ejército de Flandes (más concretamente su alto mando). Ambos estaban íntimamente conectados, en unas provincias donde la guerra, prácticamente constante desde mediados del XVI, alcanzaba entonces un momento álgido, en la lucha librada contra Francia por la hegemonía continental.

\section{El gobierno general de Flandes: entre la "naturalidad" y la "excepcionalidad"}

La irrupción del duque de Alba en los Países Bajos, al mando de un poderoso ejército, en agosto de 1567, inauguraba un período en la historia de estas provincias, que se extenderá hasta el final del dominio español. No en vano, a los pocos meses, don Fernando Álvarez de Toledo fue nombrado Gobernador General, sustituyendo a Margarita de Parma. Desde entonces, el gobierno político y militar de Flandes serían prácticamente indisolubles o, lo que es lo mismo, la política, en el sentido amplio del término, tendría una extraordinaria dimensión militar, con la presencia y actividad del ejército permanente más importante de la Monarquía Hispánica, a cuya cabeza se

d'Aumale (H. d'Orleans), Histoire des princes de Condé aux XVe et XVIIe siècles, vol. 6, 7, (París: Calmann Lévy, 1892, 1896). Su alianza con Felipe IV y su exilio en Flandes son capítulos por los que se pasa de soslayo y/o se insiste en que España nunca cumplió con la ayuda pactada y se sigue presentando al Príncipe, en el caso de su exilio, como un héroe al servicio de otro señor, y, por tanto, el adalid de todas las victorias españolas y nunca responsable de sus derrotas. Vid. Henri Malo, Le Grand Condé, (París: Tallandier, 1937); Bernard Pujo, Le Grand Condé, (París: Albin Michel, 1995); Simone Bertière, Condé, le héros fourvoyé, (París: Éditions de Fallois, 2011). Una visión más crítica sobre este personaje es la presentada por Katia Béguin, Les princes de Condé. Rebelles, courtisans et mécènes dans la France du Grand Siècle, (Seyssel: Champ Vallon, 1999), pero no se detiene en sus relaciones con la Monarquía Hispánica. Por su parte, la historiografía española no le ha prestado gran atención. Para su exilio en Flandes, es necesario citar una importante excepción, desde el ámbito anglosajón: James John Inglis-Jones, "The Battle of the Dunes, 1658: Condé, War and Power Politics", War in History, 1, 3, (1994), pp. 249-277, y The Grand Condé in exile: Power Politics in France, Spain and the Spanish Netherlands. 1652-1659, (Tesis Doctoral, Universidad de Oxford, 1994).

5 El poder informal, al margen de la estructura político-administrativa, era una práctica bastante habitual en el ejercicio de la dominación durante el Antiguo Régimen. Por ejemplo, en la corte madrileña, destacaba el papel de los predicadores y confesores del rey o la reina: Fernando Negredo del Cerro, Los predicadores de Felipe IV. Corte, intrigas y religión en la España del siglo de oro, (Madrid: Actas, 2005); Laura Oliván Santaliestra, Mariana de Austria. Imagen, poder y diplomacia de una reina cortesana, (Madrid: Editorial Complutense, 2006); Leandro Martínez Peñas, El confesor del rey en el Antiguo Régimen, (Madrid: Editorial Complutense, 2009); María del Carmen Sáenz Berceo, Confesionario y poder en la España del siglo XVII: Juan Everardo Nithard, (Logroño: Universidad de La Rioja, 2014). 
encontraba su Gobernador, con el título de Capitán General ${ }^{6}$. Podríamos, por tanto, hablar de la confluencia de dos entramados institucionales. Por un lado, la Lugartenencia General de Flandes, como institución "política" y "tradicional", creada oficialmente en 1522 -pero con precedentes en el siglo XV-, destinada al gobierno de uno de los territorios de la Monarquía Compuesta de los Austrias". Por otro, de una institución "militar" e "imperial", como era, sobre todo desde la segunda mitad del XVI, el ejército de Flandes, para la preservación, a través de las armas, tanto de los propios Países Bajos católicos como de todo el conjunto, puesto que se trataba de su pieza clave en el tablero de la política europea ${ }^{8}$.

En tiempos del Grand Condé fueron tres los Gobernadores Generales: el archiduque Leopoldo-Guillermo $(1647-1656)^{9}$, don Juan José de Austria $(1656-1659)^{10}$ y don Luis de Benavides, marqués de Caracena (1659$1664)^{11}$. Este último "ad interim", puesto que, conforme a la paz de Arras (1579), los Gobernadores de los Países Bajos debían ser príncipes de sangre $^{12}$. Ya Carlos V, en 1531, había creado tres consejos colaterales (Estado, Privado y Finanzas), para asistir al que era su máximo representante

${ }^{6}$ Vid., sobre la dimensión militar de la política en Flandes: Alicia Esteban Estríngana y José Javier Ruiz Ibáñez, "El gobierno político y militar de los Países Bajos. La gestión administrativa e institucional de un territorio "periférico" de la Monarquía Católica (siglos XVI-XVII)", Relaciones, 19, 73, (1998), pp. 115-167; Alicia Esteban Estríngana, Madrid y Bruselas. Relaciones de gobierno en la etapa postarchiducal (1621-1634), (Leuven: Leuven University Press, 2005); René Vermeir, En estado de guerra. Felipe IV y Flandes, 1629-1648, (Córdoba: Universidad de Córdoba, 2006).

7 Vid. Hugo de Schepper y René Vermeir, "Gouverneur-Général", en Les Institutions du Gouvernement Central des Pays-Bas Habsbourgeois (1482-1795), ed. E. Aerts et al., vol. 1, (Bruselas: Archives Générales du Royaume, 1995), pp. 187-208; René Vermeir, "En el centro de la periferia: los Gobernadores Generales de Flandes, 1621-1648", en España y las 17 provincias de los Países Bajos: una revisión historiográfica (XVI-XVIII), coord. Ana Crespo Solana y Manuel Herrero Sánchez, vol. 1, (Córdoba: Universidad de Córdoba, 2002), pp. 387402; "Les Gouverneurs-Généraux aux Pays-Bas Habsbourgeois", en À la place du roi. Vicerois, Gouverneurs et ambassadeurs dans les monarchies française et espagnole (XVIe-XVIIIe siècles), coord. Daniel Aznar, Guillaume Hanotin y Niels F. May, (Madrid: Casa de Velázquez, 2014), pp. 17-34.

${ }^{8}$ El gran desarrollo que ha experimentado la historia militar en las últimas décadas hace que sea muy numerosa la bibliografía sobre el ejército de Flandes, en la que podemos destacar: Geoffrey Parker, El ejército de Flandes y el Camino Español, 1567-1659, (Madrid: Alianza Editorial, 1985); Fernando González de León, The Road to Rocroi. Class, Culture and Command in the Spanish Army of Flanders, 1567-1659, (Leiden-Boston: Brill, 2009); Davide Maffi, En defensa del Imperio. Los ejércitos de Felipe IV y la guerra por la hegemonía europea (16351659), (Madrid: Actas, 2014).

9 René Vermeir, "Un austriaco en Flandes. El archiduque Leopoldo Guillermo, Gobernador General de los Países Bajos meridionales (1647-1656)", en La dinastía de los Austria: las relaciones entre la Monarquía Católica y el Imperio, coord. José Martínez Millán y Rubén González Cuerva, vol. 1, (Madrid: Polifemo, 2011), pp. 583-608.

10 Josefina Castilla Soto, Don Juan José de Austria (hijo bastardo de Felipe IV): Su labor política y militar, (Madrid: UNED, 1992), pp. 103-154; José Calvo Poyato, Juan José de Austria. Un bastardo regio, (Barcelona: Plaza \& Janés, 2002), pp. 71-84; Ignacio Ruiz Rodríguez, Don Juan José de Austria en la Monarquía Hispánica: entre la política, el poder y la intriga, (Madrid: Dykinson, 2007), pp. 179-209.

11 José I. Benavides, Milicia y diplomacia en el reinado de Felipe IV. El marqués de Caracena, (Astorga: Akrón, 2012), pp. 523-719.

12 Trata particularmente esta cuestión Alicia Esteban Estríngana, "El 'gobierno de los príncipes' en los Países Bajos católicos. La sucesión del cardenal-infante al frente de las provincias obedientes (1641-1644)", Anali di Storia moderna e contemporanea, 7, (2001), pp. 166-222. 
en dichas tierras ${ }^{13}$. Pero, sobre todo, contaba con una serie de colaboradores y consejeros, civiles, militares y eclesiásticos, entre los que destacaban aquellos que, ostentando distintos oficios y procedentes de diversas instituciones, tenían algo en común, el ser, ante todo, ministros de su majestad católica ${ }^{14}$. Por esta razón, aun compartiendo algunas de sus características, no se les podría considerar, de forma estricta, "autoridades informales"15.

El puesto de Gobernador General de Flandes, sobre todo cuando lo ejercía un príncipe de la casa de Austria, era demasiado importante para que el rey no situara a su lado a personas de confianza que, además de asesorarle, debían controlarle. El Secretario de Estado y de Guerra tuvo tradicionalmente esta misión, hasta mediados del XVII ${ }^{16}$, o personajes como Ambrosio Spínola, Maestro de Campo General, con Isabel Clara Eugenia (aunque su poder venía de la época de los archiduques) ${ }^{17}$, o Pierre Roose, jefe-presidente del Consejo Privado, entre 1632 y $1653^{18}$. Marginado este último, con LeopoldoGuillermo, destacaron, al lado del archiduque y de don Juan, respectivamente, el conde de Fuensaldaña (ministro del Consejo de Guerra en Madrid) y el marqués de Caracena (del Consejo de Estado) ${ }^{19}$. Ambos eran Gobernadores de las Armas del ejército de Flandes, y, por tanto, segundos en el escalafón militar. Además, para un mayor control del archiduque, el conde don Alonso Pérez de Vivero también fue nombrado su mayordomo mayor.

Resulta muy ilustrativa la misiva enviada por Felipe IV a su primo, el 8 de noviembre de 1647. Fuensaldaña debía ser el hombre de confianza de Leopoldo-Guillermo y no solo en las cuestiones militares. Puesto que se trataba del "primer ministro cerca de vuestra alteza, parece necesario decía- que se comuniquen siempre con él los negocios de importancia que se

\footnotetext{
13 Michel Baelde y René Vermeir, "Conseil d'État", en Les Institutions du Gouvernement Central des Pays-Bas Habsbourgeois (1482-1795), ed. E. Aerts et al., vol. 1, (Bruselas: Archives Générales du Royaume, 1995), pp. 257-274; Hugo de Schepper, "Conseil Privé", en Ibid., pp. 287-317; Hernam Coppens, "Conseil des Finances", en Ibid., vol. 2, pp. 497-521.

14 Joseph Lefèvre, "Le Ministère Espagnol de I'Archiduc Albert 1598-1621", Bulletin de I'Académie Royale de Archéologie de Belgique, 1, (1924), pp. 202-224; Piet Lenders, "Services d'assistance et de contrôle auprès des Gouverneurs des Pays-Bas Méridionaux (XVIIe-XVIIIe siècle)", Archives et Bibliothèques de Belgique 61, 3/4, (1990), pp. 447-468; Vermeir, En estado de guerra, pp. 7-8.

${ }^{15}$ Como un poder informal actuó, en cambio, el conde de Schwarzenberg, hombre de confianza del archiduque Leopoldo, hasta que, a instancias de Fuensaldaña, Felipe IV ordenó su salida de Flandes. Vid. Vermeir, "Un austriaco en Flandes...", pp. 583-608.

16 Piet Lenders, "Secrétairerie d'État et de Guerre", en Les Institutions du Gouvernement Central des Pays-Bas Habsbourgeois (1482-1795), ed. E. Aerts et al., vol. 1, (Bruselas: Archives Générales du Royaume, 1995), pp. 383-395.

17 Esteban Estríngana, Madrid y Bruselas.

18 Alicia Esteban Estríngana, "La crise politique de 1629-1633 et le début de la prééminence institutionnelle de Pierre Roose dans le gouvernement général des Pays-Bas Catholiques", Belgisch Tijdschrift voor Filologie en Geschiedenis, 76, (1998), pp. 939-977; René Vermeir, "Les limites de la monarchie composée: Pierre Roose, factotum du comte-duc d'Olivares aux Pays-Bas espagnols", Dix-Septième siècle, 240, (2008), pp. 495-518.

19 Vid. bibliografía citada en notas 9-11.
} 
fueren ofreciendo, interviniendo en los Consejos o Juntas de Estado o Guerra $(\ldots)$, donde mientras no huviere otro ministro mío de mayor grado siempre le tocará el primer lugar". Por otra parte, añadía su majestad, "holgaré que la comunicación de los negocios se estiendan también a los del país, en que sus noticias y celo puedan aliviar los cuidados de vuestra alteza"20.

Aunque en un segundo plano, hay que mencionar a otros dos ministros, Agustín Navarro Burena, Secretario de Estado y de Guerra entre 1648 y 1655, y don Alonso de Cárdenas (del Consejo de Estado en Madrid), quien, tras su embajada en Londres, recaló en Bruselas, en 1655, para seguir asistiendo en los negocios de Inglaterra ${ }^{21}$. De esta forma, en 1658, el Príncipe de Condé, en su instrucción a Pierre Lenet (su mano derecha), que enviaba a la corte madrileña para defender sus intereses, no se olvidaba de señalar la opinión que debía ofrecer sobre este individuo: "Dira du bien de don Alonço de Cárdenas, comme d'un homme bien intentionné qui sçait les affaires d'Angleterre et qui tasche à apprendre celles de par deçà; mais comme d'un homme vieil, et par conséquent lent, naturellement doux, et par cette raison ne voulant rien pousser avec vigueur"22.

También el archiduque Leopoldo-Guillermo, don Juan José de Austria, el conde de Fuensaldaña y el marqués de Caracena se encontraban al frente del poderoso ejército de Flandes, ocupando los primeros puestos de la cúpula militar. Había sido en 1631 cuando, en la cadena de mando, inmediatamente después del Capitán General se situó un nuevo cargo, el Gobernador de las Armas, que desplazaba, al tercer lugar, al Maestro de Campo General23. Todos los años, este ejército salía a campaña, en el que era uno de principales teatros de operaciones de la guerra Franco-Española, a la vez que sus provincias debían proporcionarle alojamiento los meses de invierno.

Formadas por unos 50.000-60.000 hombres, estas tropas consumían ingentes cantidades de dinero, tanto de las remesas que venían de España, cada vez más escasas, como de la contribución de los propios Países Bajos ${ }^{24}$.

20 Archivo Histórico Nacional (AHN), Estado, leg. 1414, Felipe IV a Leopoldo-Guillermo, 8-XI1647.

${ }^{21}$ Alonso de Cárdenas, La revolución inglesa (1638-1656), ed. Ángel Alloza y Glyn Redworth, (Madrid: Biblioteca Nueva, 2011), pp. 19-20.

22 Pierre Lenet, Mémoires, ed. Michaud y Poujoulat, (París: Chez l'éditeur du Commentaire Analytique du Code Civil, 1838), p. 626 (Instrucción para Lenet yendo a España, 28-V-1658).

23 Esteban Estríngana, Madrid y Bruselas, pp. 158-176; Vermeir, En estado de guerra, pp. 4044.

24 A partir de 1640, a medida que disminuían las remesas que venían desde España, al aumentar los frentes de guerra con las revueltas de Cataluña y Portugal, tuvo que incrementarse la contribución de los Países Bajos al esfuerzo militar. Vid. Maffi, En defensa del Imperio, pp. 428-433, 438, 440-466. Sobre la hacienda del ejército de Flandes, formada por dos cajas, la caja militar -la principal, que, a través de la Pagaduría General, gestionaba el dinero que llegaba de España y las contribuciones voluntarias de las provincias, las cuales crecieron exponencialmente después de 1640- y la caja de Finanzas -que administraba, a través del Consejo de Finanzas, las contribuciones fijas de las provincias-, vid., además, Alberto Marcos Martín, "España y Flandes (1618-1648): la financiación de la guerra", en Calderón de la Barca y la España del Barroco, ed. José Alcalá-Zamora y Ernest Belenguer, vol. 
Fuensaldaña también se hizo cargo de la Superintendencia de Hacienda, que limitaba las atribuciones que sobre el gasto militar tenía el Capitán General; en cambio, Caracena, conforme a las instrucciones dadas por su majestad a don Juan de Austria, debía compartir esta prerrogativa con una Junta, compuesta por él mismo, Alonso de Cárdenas y Charles Hovynes, el entonces jefe-presidente del Consejo Privado ${ }^{25}$. De todas formas, parece que esta Junta de Hacienda nunca llegó a ponerse en funcionamiento, debido a la oposición de Caracena ${ }^{26}$, quien seguirá resistiéndose a su formación, ya nombrado Gobernador General27.

Aquellos eran tiempos de guerra. Por ende, los asuntos militares se situaron en primer plano, a lo que también contribuyó la presencia de Condé y sus hombres. Es más, lo acaecido entre 1651 y 1659, pone en evidencia el contraste entre la "naturalidad", es decir, el gobierno de las instituciones y ministros ordinarios, y la "excepcionalidad", que entonces se produjo. Y es que la política de Flandes estuvo, no en poca medida, supeditada y controlada por el Grand Condé. Logró una posición y un poder que no disfrutaron otros aliados y exiliados del rey católico, como eran entonces, también en estas provincias, el duque de Lorena y Carlos II de Inglaterra ${ }^{28}$. Todo ello sin ostentar ningún cargo dentro de la estructura político-militar de la Monarquía Hispánica, pese a la insistencia errónea, por parte de la historiografía francesa, de que el Príncipe fue nombrado generalísimo del ejército español, el 25 de noviembre de $1652^{29}$.

Podemos afirmar que la alianza entre el Grand Condé y Felipe IV fue buscada y deseada por ambas partes. En su lucha por la supremacía europea,

2, (Madrid: Centro de Estudios Políticos e Institucionales, 2001), pp. 15-39; Alicia Esteban Estríngana, Madrid y Bruselas; Guerra y finanzas en los Países Bajos católicos: de Farnesio a Spinola (1592-1630), (Madrid: Ediciones del Laberinto, 2002); "El control y la fiscalización del gasto militar", en Historia militar de España: Edad Moderna. Escenario europeo, coord. Luis Ribot, (Madrid: Ministerio de Defensa, 2013), pp. 259-284.

25 Maffi, En defensa del Imperio, pp. 326-327. Tanto la Superintendencia como la Junta de Hacienda actuaban sobre la caja militar (vid. bibliografía citada nota 24).

26 Castilla Soto, Don Juan José de Austria, p. 110; Benavides, Milicia y diplomacia, pp. 526530.

27 AGS, Estado, leg. 2197, Junta de Estado, 18-I-1659.

28 Sobre el duque de Lorena y su exilio en Flandes: Jean-Charles Fulaine, Le Duc Charles IV de Lorraine et son armée, 1624-1675, (Metz: Editions Serpenoise, 1997); Charles J. A. Leestmans, Charles IV, duc de Lorraine (1604-1675). Une errance baroque, (Lasne: Par Quatre Chemins, 2003); René Vermeir, "Charles IV de Lorraine et I'Espagne 1634-1659", Hémecht. Revue d'histoire luxembourgeoise, 62, (2010), pp. 393-402. En cuanto a Carlos II de Inglaterra: Eva Scott, The Travels of the King: King Charles II in Germany and Flanders 16541660, (Londres: Archibald Constable and Company, 1907); Hester W. Chapman, The Tragedy of Charles II in the Years 1630-1660, (Londres: J. Caspe, 1964); Josefina Castilla Soto, "Las relaciones entre Felipe IV y Carlos II de Inglaterra, durante el protectorado de Cromwell (16561659)", Espacio, Tiempo y Forma, Serie IV, Historia Moderna, 2, (1989), pp. 111-124; Anna Keay, The Magnificent Monarch. Charles II and the Ceremonies of Power, (Londres, Nueva York: Bloomsbury Continuum, 2008), pp. 45-79.

29 Este dato se repite desde duc d'Aumale, Histoire des princes, vol. 6, p. 257. En cambio, sí hubo rumores en Francia sobre la concesión de este título, que iban en contra de Príncipe, puesto que trataban de poner de manifiesto, tras su abandono de París, su paso al servicio de Felipe IV, algo que realmente solo se produjo con la caída de Burdeos. Así lo señala Lenet, Mémoires, pp. 587-588 (Lenet a Condé, 13-XII-1652). 
la Monarquía Católica no podía desaprovechar las revueltas internas en Francia, que se desarrollaban desde 1648, para restar, de esta forma, fuerzas al enemigo ${ }^{30}$. La ocasión que se presentaba no era nueva. Hasta el triunfo del Absolutismo, no solo era un derecho sino incluso un deber de la nobleza francesa el rebelarse contra los manipuladores de la autoridad real, que ponían en peligro la salud del reino y, con ello, los privilegios del estamento nobiliario. Este "deber de revuelta" no escatimaba el uso de la violencia ni la alianza con el extranjero y especialmente con la Monarquía Hispánica, dado su poder y su rivalidad con la Corona francesa ${ }^{31}$. España ya había entrado en la Fronda Parlamentaria, en 1649, y, al año siguiente, firmado dos tratados, en la conocida como Fronda de los Príncipes, para proporcionar ayuda económica y militar a los frentes septentrional y meridional de la revuelta. $Y$ aunque no habían sido pocos los problemas con el mariscal Turenne ${ }^{32}$, las autoridades de Flandes, al igual que la corte madrileña, vieron con muy buenos ojos esta nueva oportunidad, en la que era el propio Príncipe de Condé quien solicitaba la ayuda del rey católico.

El 26 de octubre de 1651, Leopoldo-Guillermo firmó, en Maubeuge, un tratado con La Roque, enviado por Condé, para reactivar el polo septentrional de la Fronda ${ }^{33}$. Ya entonces, se estaba negociando en Madrid, por Pierre Lenet, un tratado general. Su firma tuvo lugar el 6 de noviembre, en el que quedaron incluidas las cláusulas pactadas por el archiduque. El enemigo común no era Luis XIV sino Mazarino. Ambas partes se comprometían a mantener la alianza hasta que se lograse la paz entre ambas coronas y, con ella, la satisfacción de los intereses de Condé. Asimismo, la Monarquía Hispánica se obligaba a proporcionar importantes asistencias, para impulsar la revuelta en el norte y sur de Francia: 5.000 hombres y artillería, en la frontera de los Países Bajos, 30 barcos de guerra, con 4.000 hombres, en la ribera de Burdeos, y sumas de dinero que ascendían a la ingente cantidad de 120.000 reales de a ocho mensuales, más otros 550.000, a pagar tras la firma del tratado 34 .

30 Cientos de páginas se han escrito sobre la Fronda, por parte de historiadores franceses y anglosajones, muy particularmente entre 1950 y 1980. Entre las obras más recientes, podemos citar, Jean-Marie Constant, C'était la Fronde, (París: Flammarion, 2016). En estos estudios, la Monarquía Hispánica se presenta como un actor muy secundario del que es difícil, además, conocer de forma precisa, cuál, cómo, cuándo y por qué fue su actuación. Podemos citar una excepción: Hélène Thiéry, "À la découverte d'un acteur de la Fronde à Bordeaux: la mission du baron de Vatteville (1649-1653)", Annales du Midi, 121, 265 (2009), pp. 37-56. Por parte de los historiadores españoles e hispanistas tampoco se ha prestado mucha atención a la intervención española en la Fronda, salvo Maffi, En defensa del Imperio, pp. 112-128 y Benavides, Milicia y diplomacia, pp. 399-416, 497-520.

31 Jouanna Arlette, Le devoir de révolte. La noblesse française et la gestation de l'État moderne, 1559-1661, (París: Fayard, 1989).

32 AGS, Estado, leg. 2073, exp. 151, Leopoldo-Guillermo a Felipe IV, 25-VI-1650 (problemas en campaña con Turenne), Ibid., leg. 2076, exp. 113, Leopoldo-Guillermo a Felipe IV, 6-V1651 (problemas con el elector de Colonia por haberse alojado las tropas de Turenne en Lieja).

${ }^{33} \mathrm{Ibid}$., leg. 2177, copia del tratado que el archiduque negoció con monsieur la Roque, enviado del príncipe de Condé, Maubeuge, 26-X-1651.

34 "Tratado ajustado entre la Magestad Cathólica del señor D. Phelipe IV, de una parte, y el señor Luis de Borbón, Príncipe de Condé, el Príncipe de Conti y sus demás aliados, de otra". Figura en Joseph Antonio de Abreu y Bertodano, Colección de los tratados de paz [...]. Reinado 
Esta alianza ya implicaba de lleno a Flandes. Aunque sus efectos serán mayores a partir de 1652 y, sobre todo, de 1653. Cuando se firmó, el frente principal de la revuelta se situaba en la Guyena, donde estaba Condé. Ya en marzo de 1652, Luis II de Borbón se dirigió hacia el norte, tratando de ganar para su causa la capital, de donde había salido la corte. En octubre abandonó París, incrementando todavía más la presión sobre las autoridades de Flandes, al dirigirse hacia su frontera. Una decisión lógica para el Príncipe, que trataba de no estar lejos de la capital francesa, pero que ya fue cuestionada por Madrid, que hubiera preferido su retorno a la Guyena, "por tenerle más a la mano vuestra majestad y estar él en parte donde pudiese recibir más promptamente los socorros" ${ }^{35}$. Tras la caída de Burdeos, lo que parecía una situación extraordinaria, se convirtió en cotidiana, puesto que Condé hubo de instalarse de forma permanente en Flandes. Al igual que en 1651, su exilio suponía el canto de cisne de una cultura nobiliaria que, junto con el "deber de revuelta", también permitía servir a un señor diferente al natural, en el caso de sentirse maltratado por este. En consecuencia, no habían sido pocos los nobles franceses que, antes de Condé, se habían exiliado a las tierras del rey católico y, muy particularmente, a Flandes ${ }^{36}$.

La corte madrileña, encabezada por Felipe IV y don Luis de Haro, siempre se esforzó por mantener buenas relaciones con el Grand Condé, consintiendo y alentando, muchas veces, su autoridad en los Países Bajos ${ }^{37}$. Y es que la alianza con el Príncipe era necesaria para la continuación de la guerra civil en Francia. Se logró hasta 1653, contribuyendo a que el año anterior fuera un auténtico "annus mirabilis" para la Monarquía Hispánica en la contienda europea ${ }^{38}$. Solo tras la rendición de Burdeos, que trastocaba todos los planes, Madrid llegó a cuestionarse este pacto, influida por las insistentes quejas que ya venían de Flandes. Tuvo lugar el 19 de septiembre, en la reunión de la Junta de Estado ${ }^{39}$, y muy particularmente, en la celebrada nueve días después:

"Aunque el Príncipe ha perdido tanto [...], cree la Junta que no es poco lo que ha perdido vuestra majestad, caiéndosele sobre los brazos y las flacas fuerzas de aquellas provincias del País Bajo un príncipe desheredado, dificultoso por su condición, calidades en que puede

de Phelipe IV. Parte IV, (Madrid: Por Antonio Marín, Juan de Zúñiga y la viuda de Peralta, 1749), pp. 110-137.

${ }^{35}$ AGS, Estado, leg. 2078, exp. 254, Junta de Estado, 8-XI-1652.

36 Vid. Serge Brunet y José Javier Ruiz Ibáñez, "Los exilios franceses en la Monarquía Hispánica", en Los exiliados del rey de España, coord. José Javier Ruiz Ibáñez e Igor Pérez Tostado, (Madrid: Fondo de Cultura Económica, 2015), pp. 131-159; Yves Junot y Marie Kervyn, "Los Países Bajos como tierra de recepción de exiliados", en Ibid., pp. 207-231.

37 Sobre el círculo cortesano en tiempos de Felipe IV y, muy particularmente, la figura de don Luis de Haro, vid. los recientes estudios de Rafael Valladares (ed.), El mundo de un valido. Don Luis de Haro y su entorno, 1643-1661, (Madrid: Marcial Pons, 2016), y Alistair Malcolm, Royal Favouritism and the Governing Elite of the Spanish Monarchy 1640-1665, (Oxford: Oxford University Press, 2017), este último con diversas referencias a Condé.

38 Maffi, En defensa del Imperio, p. 126.

${ }^{39}$ AGS, Estado, leg. 2080, exp. 63, Junta de Estado, 19-IX-1653. 
compararse con el duque de Lorena, pero de muchas más peligrosas consequencias para tenerle dentro de casa, por su ambición de gloria y por tener un ánimo capaz de interprender qualquiera gran negocio"40.

Sucedió, sin embargo, todo lo contrario. La alianza entre Condé y la corte madrileña se fortaleció durante sus años de exilio. Contribuyeron las simpatías de don Luis de Haro hacia su persona ${ }^{41}$. Asimismo, la corte consideraba preciso seguir cumpliendo con él, como muestra de gratitud, pues, como recordaba, el 25 de octubre de 1653, "todo lo que ha perdido el Príncipe ha facilitado nuestras ganancias"42. Pero también era una cuestión de prestigio y de honor, el que Felipe IV mantuviera la palabra dada, ya que Condé se había situado "devajo de su protección"43.

Por otro lado, se le seguía teniendo por un buen aliado. Se valoraba su destreza militar, alabada incluso por sus adversarios en Flandes. Las palabras de Barrionuevo, transcritas al principio, tenían lugar tras conocerse el fracaso del sitio de Arras. Según nuestro cronista, "dícese que el de Fuensaldaña se retiró de lo de Ras [sic] cobardemente, sin disparar arcabuz [...], dejando al Príncipe de Condé peleando como un león en medio del enemigo, donde, haciendo maravillas, le mató infinita gente ${ }^{\prime 44}$. Aunque frustrado, este hecho de armas sirvió para engrandecer todavía más la leyenda del Grand Condé, puesto que todas las informaciones recibidas en Madrid, incluidas las del archiduque y Fuensaldaña, destacaban su actuación ${ }^{45}$.

Sus hazañas militares no dejaban de ser una de las principales manifestaciones de su lealtad al rey de España, circunstancia también muy apreciada. Condé insistía constantemente en ello, en sus cartas a Felipe IV y don Luis de Haro. Por ejemplo, en 1656, tras la enhorabuena que le había enviado el monarca, por su actuación en Valenciennes, le respondía en estos términos: "Je la supplie très humblement de croire que je contineray de la servir avec la mesme fermeté, et que je méspriseray toutes les choses du monde pourvu que je me puisse rendre digne de l'honneur de son estime et de sa protection" ${ }^{\prime 46}$.

El 12 de septiembre de 1656, por los avisos que llegaban de Francia, el barón de Watteville (Capitán General de Guipúzcoa) comentaba a don Luis de Haro, que Mazarino estaba esperando "si el Príncipe de Condé topa un

\footnotetext{
40 Ibid., exp. 75, Junta de Estado, 28-IX-1653.

41 Esta estrecha amistad se puso especialmente de manifiesto en la enconada defensa que don Luis de Haro hizo de los intereses del Príncipe en las negociaciones de la Paz de los Pirineos. Rafael Valladares, "Haro sin Mazarino. España y el fin del 'orden de los Pirineos' en 1661", Pedralbes, 29, (2009), pp. 371-372.

42 AGS, Estado, leg. 2080, exp. 81, Junta de Estado, 25-X-1653.

43 Ibid., leg. 2083, exp. 18, Junta de Estado, 18-II-1654.

44 De Barrionuevo, Avisos, vol. 1, pp. 85-86 (10-X-1654).

45 AGS, Estado, Leg. 2083, exp. 119, Leopoldo-Guillermo a Felipe IV, 28-VIII-1654; Ibid., Fuensaldaña a Felipe IV, 28-VIII-1654; Ibid., Consejo de Estado, 7-X-1654.

46 Ibid., leg. 2088, exp. 165, Condé a Felipe IV, 6-X-1656.
} 
balazo que le mate. Y así dize su eminencia que se cansa ya de que las balas no topen con el Príncipe"47. He aquí otra razón por la que seguía siendo un buen aliado para la Monarquía Hispánica. Luis II de Borbón era una de las grandes preocupaciones del primer ministro francés. Se consideraba que el país vecino no estaba completamente apaciguado y que la chispa de la revuelta podía volver a prender, mientras Condé no se reconciliase con Luis XIV. No en vano, fueron frecuentes los conatos, de los que se hizo eco Jerónimo de Barrionuevo ${ }^{48}$. Además, peor parecía tenerlo como enemigo, con sus tropas, que incrementarían las fuerzas de Francia, muy particularmente en el frente de Flandes.

Para ayudar a conformar y mantener este estado de opinión, el Príncipe contó con una nutrida representación en Madrid, encabezada por una especie de "embajador", puesto en que destacó, por su duración, el conde de Fiesque (1653-1658, cuando falleció). De todas formas, pese a estas buenas relaciones, la corte española fue consciente, como veremos, de los problemas que suscitaban la presencia de Condé, sus tropas y su clientela en aquellas provincias. Por su parte, el Príncipe y sus enviados a Madrid no dejaron de reclamar de forma amarga porque aquella no cumplía con las asistencias pactadas, algo que era muy difícil, dada la situación de crisis de la hacienda real. El conde de Fiesque, en abril de 1654, representaba a don Luis de Haro, "que es absolutamente necesario mudar el proceder que se tiene con su alteza, el Príncipe, mi señor, y darle más medios que hasta aora, para mantener su Partido, porque de otra manera su ruyna es ynevitable dentro de poco tiempo"49. Tres años más tarde, Condé agradecía al valido español el recibo de letras de cambio de 50.000 escudos. Pero, añadía, que "sans quelque nouvelle assistance il est difficile que je puisse mettre mes trouppes en aussy bon éstat que je voudrois qu'elles fussent pour bien servir le roy cette campagne"

Sin duda, el amparo de Felipe IV resultó clave para el desarrollo de la "autoridad informal" del Príncipe en Flandes. Pero tampoco podemos olvidar otros factores, los cuales influyeron también en la actitud adoptada por la corte madrileña. Eran su propio prestigio, pues nada menos que se trataba del primer príncipe de sangre francés y el único capaz de hacer frente a Mazarino, y su red de clientelismo y patronazgo. Como reminiscencia de una época, el de la nobleza feudal, que se resistía a desaparecer frente al avance del Absolutismo, en la revuelta y aún en el exilio, bajo su protección y tutela se mantuvo un nutrido número de personas, que iba desde sus familiares y miembros de la alta nobleza, hasta simple soldados. Es más, su clientela en

\footnotetext{
47 Real Academia de la Historia (RAH), Colección Salazar y Castro, K-34, f. 219r., Watteville a Luis de Haro, 12-IX-1656.

48 De Barrionuevo, Avisos, vol. 1, pp. 166, 172, 190; Ibid., vol. 2, pp. 235, 239; Ibid., vol. 3, pp. 164, 175; Ibid., vol. 4, pp. 98, 105-106, 122-123, 129, 202.

${ }^{49}$ AGS, Estado, leg. 2265, Fiesque a Luis de Haro, 24-IV-1654.

50 Bibliothèque nationale de France (BNF), Département des manuscrits, Français 6731, f. 254, Condé a Luis de Haro, 28-IV-1657.
} 
Flandes creció tras la caída de Burdeos, puesto que muchos de sus seguidores en el frente meridional de la Fronda, comenzando por su esposa e hijos, no se acogieron al perdón real y le siguieron en el exilio ${ }^{51}$. Por ejemplo, al mando de sus tropas, en 1659, se encontraban destacados nobles como el marqués de Persan o los condes de Guitaut, de Tourville, de Boutteville y de la Suze ${ }^{52}$. Una clientela solo fiel a su señor, que también contribuía a trastocar el gobierno de los Países Bajos meridionales. En este sentido, es tremendamente expresivo lo señalado por don Baltasar Mercader, enviado a Madrid, por el archiduque Leopoldo-Guillermo, en 1654:

"Que el govierno no puede ser comforme a la razón ni a la justicia distributiva, por valerse aquellos súbditos de la intercesión del Príncipe, de la Princesa y de sus validos, concediéndoseles, por su medio, lo que piden; siendo de ordinario lo menos benemérito y faltando a lo justo, se les abre camino para hazer echuras, tener obligados, de tirar así todo el dinero del pays y de partir la autoridad su alteza [el archiduque]"53.

Esta red clientelar se extendió a los propios súbditos de su majestad católica en Flandes, alcanzando a altos cargos de la administración. En 1657, Condé daba instrucciones al conde de Fiesque, para que apoyara, en su nombre, ante don Luis de Haro, la pretensión de Francisco Juan Robles, entonces obispo de Yprès, a la diócesis de Gante ${ }^{54}$. Cuatro años antes, había sido el propio Príncipe quien había escrito a Felipe IV, recomendando al conde de Saint Amour como gobernador de la provincia de Namur ${ }^{55}$.

Según el duque d'Aumale, ya en tiempos del archiduque Leopoldo, "les meilleurs officiers au service du roi catholique, Garcies, le prince de Ligne, le comte de Hennin, lui étaient absolument dévoués"56. En mayo de 1654, Fiesque relataba al Príncipe cómo don Fernando de Quesada y Mendoza, conde de Garcies (General de Infantería, 1649-1656), había escrito a don Luis de Haro, informándole de las ofensas que Condé sufría por parte de Fuensaldaña. "Cette lettre a mis en grande colère monsieur dom Louis contre le comte de Fuensaldagne et a faict qu'il luy a éscrit une lettre toute plaine de la mauvaise satisffaction que le roy et luy avoient de son mauvais procéder"57. Por su parte, Condé señalaba a Fiesque, en 1655, "que l'armée d’Espagne est si peu pauvre d'officiers généraux que vaillent quelque chose, qu'il n'y en a pas un, à la réserve du prince de Ligne (General de Caballería,

\footnotetext{
51 Béguin, Les princes de Condé, pp. 112-146, 395-440.

52 AGS, Estado, leg. 2095, exp. 100, relación de las tropas del Príncipe de Condé (noviembre de 1659).

53 Ibid., leg. 2083, exp. 18, Junta de Estado, 18-II-1654.

54 BNF, Département des manuscrits, Français 6731, f. 265, Condé a Fiesque, 23-IX-1657.

55 AHN, Diversos-Colecciones, leg. 10, exp. 835.

56 Duc d'Aumale, Histoire des princes de Condé, vol. 6, p. 335.

57 Archives du musée Condé au château de Chantilly (AC), série P., vol. 14, f. 138, Fiesque a Condé, $16-\mathrm{V}-1654$.
} 
1654-1659)"58. De todas formas, nada menos que fue el marqués de Caracena quien principalmente estrechó lazos con el Grand Condé.

Si nos detenemos en su impacto en Flandes se deben distinguir dos etapas: una, durante el gobierno de Leopoldo-Guillermo y Fuensaldaña, y otra, mientras lo hicieron don Juan José de Austria y Caracena.

\section{Leopoldo-Guillermo, Fuensaldaña y Condé: el conflicto permanente}

El archiduque y Fuensaldaña compartían, a la altura de 1655, un mismo deseo: abandonar Flandes. Pesaba la mala relación entre ambos, así como el pesimismo ante la marcha de la guerra, por la escasez de medios que venían de España. También, y mucho, el Príncipe de Condé. Ya en noviembre de 1654, Fuensaldaña se lo había planteado a don Luis de Haro ${ }^{59}$. En enero se dirigió a Felipe IV. Intentaba seguir sus órdenes "de correr con el Príncipe, no obstante su estravagancia, en la mejor forma que fuese posible". Pero, se quejaba, "quan imposible es, que a menos de abandonar enteramente sus intereses [de su majestad] y atender solo a los del Príncipe, el conservarse con él en buena correspondencia". Por tanto, sugería al rey, si lo consideraba conveniente, su reemplazo en Flandes ${ }^{60}$. En los meses siguientes, ya sin rodeos, le señaló su voluntad de abandonar el cargo ${ }^{61}$. Insistió, el 27 de noviembre. No escondía los problemas con el archiduque. Asimismo, "los accidentes que en este tiempo se han ofrecido, [han] dispuesto el govierno de estos estados de suerte que a mí no me queda del puesto de Gobernador de las Armas otra cosa que el título y la culpa de quanto subcede mal en ellos". La razón: "se ha introducido la autoridad del Príncipe de Condé, que al principio pareció pasajera y oy la han establecido los accidentes en estos países"62.

Cuando su última carta fue recibida en Madrid, en enero de 1656, el futuro de Fuensaldaña ya estaba decidido. A la corte madrileña había llegado la instrucción dada por Leopoldo-Guillermo a don Gaspar Bonifaz, que debía venir a España para informar de los problemas en Flandes y su deseo de ser sustituido. Según señalaba, "se confundía el govierno político y militar, no viniendo yo a ser en estos estados governador dellos, pues pretendía en todo partir conmigo la authoridad del Príncipe"63. Aun consciente de las dificultades

\footnotetext{
58 Duc d'Aumale, Histoire des princes de Condé, vol. 6, p. 741 (Condé a Fiesque, 21-VII-1655). 59 AGS, Estado, leg. 2083, exp. 159, Consejo de Estado, 30-XII-1654 (tres cartas de Fuensaldaña a Luis de Haro, 6-XI-1654, 11-XI-1654 y 25-XI-1654).

60 Ibid., leg. 2084, exp. 57, Fuensaldaña a Felipe IV, 5-I-1655.

61 Ibid., leg. 2266, exp. 46, Felipe IV a Fuensaldaña, 17-IV-1655 (en respuesta a sus cartas de 27-II-1655 y 4-III-1655).

62 Ibid., leg. 2087, exp. 4, Fuensaldaña a Felipe IV, 27-XI-1655.

63 Ibid., leg. 2085, exp. 137, instrucción de Leopoldo-Guillermo a Gaspar Bonifaz, 12-IX-1655. Dicha instrucción llegó, a través del secretario de Estado y Guerra, Martín de Galarreta, y fue vista por la corte madrileña, antes que el propio Bonifaz, que no lo hará hasta marzo de 1656.
} 
que acarreaba, el Consejo de Estado, reunido el 11 el noviembre, no cambió su postura sobre Condé. En cuanto a la licencia que solicitaba el archiduque, puesto que también la pedía Fuensaldaña, "representa el Consejo a vuestra majestad que su alteza y el conde no es dudable que son incompatibles y que para la conservación de aquellos países es necesario y forzoso que salga uno de los dos, el que vuestra majestad tuviere por más conveniente"64. Felipe IV decidió la sustitución de Fuensaldaña por el marqués de Caracena, entonces Gobernador de Milán, tratando de complacer tanto al archiduque como al Príncipe ${ }^{65}$. Pero Leopoldo-Guillermo siguió perseverando en su idea. En febrero de 1656, a consulta del Consejo de Estado, el rey aprobó su reemplazo por don Juan José de Austria, nuevo Gobernador y Capitán General de los Países Bajos católicos ${ }^{66}$.

¿Cómo se había llegado a esta situación? Desde finales de 1651 el poder de Condé no había dejado de desarrollarse. Mientras duró la guerra civil en Francia, aun a veces a regañadientes y con las dificultades que imponía la escasez de medios, el archiduque y Fuensaldaña trataron de cumplir las órdenes de la corte madrileña. Esta no dudó en la necesidad de apoyar militarmente al Príncipe en el norte de Francia, pero tampoco descartó, en un primer momento, el aprovechar la coyuntura para recuperar plazas en Flandes ${ }^{67}$. Solo a partir de junio de 1652, ante la presión de Condé, Madrid insistió en anteponer los intereses del Príncipe a los de su majestad ${ }^{68}$.

En el tiempo que Luis II de Borbón se mantuvo en París, entre abril y octubre de 1652, ya surgió el enfrentamiento y la desconfianza con el archiduque y Fuensaldaña. Uno y otros iniciaron conversaciones con la corte francesa, a espaldas de la otra parte; además, en opinión de Condé, desde Flandes no se le prestaba la ayuda necesaria, mientras que para sus autoridades se hacía cuanto se podía69. Este segundo reproche fue una constante a partir de entonces. De todas formas, las campañas de 1652 y 1653 estuvieron, en buena medida, subordinadas al Príncipe. En ambas, Fuensaldaña entró en Francia para apoyarle, aunque por poco tiempo, debido, entre otras razones, a su falta de entendimiento ${ }^{70}$. Asimismo, las tropas de Condé fueron reforzadas con soldados del ejército de Flandes. En 1652 se le

\footnotetext{
64 Ibid., exp. 135, Consejo de Estado, 11-XI-1655.

65 RAH, Colección Salazar y Castro, A-92, f. 96-99, Felipe IV a Lepoldo-Guillermo, 1655.

66 AGS, Estado, leg. 2087, exp. 30, Consejo de Estado, 2-II-1656.

67 Ibid., leg. 2262, Felipe IV a Leopoldo-Guillermo, 20-II-1652.

68 Ibid., Felipe IV a Leopoldo-Guillermo, 30-VI-1652; Ibid., Felipe IV a Leopoldo-Guillermo, 16-VII-1652; Ibid., leg. 2264, Felipe IV a Leopoldo-Guillermo, 26-IV-1653.

69 Ibid., leg. 2078, exp. 179, Fuensaldaña a Leopoldo-Guillermo, 18-VII-1652; Ibid., exp. 198, Junta de Estado, 31-VIII-1652; Ibid., exp. 224, Leopoldo Guillermo a Felipe IV, 17-VIII-1652; AC, série P., vol. 12, f. 238-239, Fuensaldaña a Condé, 15-V-1655; Ibid., f. 331-336, Lenet a Luis de Haro, 10-VIII-1652.

70 Maffi, En defensa del Imperio, pp. 123, 127.
} 
proporcionaron más de 15.000 hombres y, al año siguiente, 5.000, a la vez que se le unieron las huestes del duque de Lorena ${ }^{71}$.

En octubre de 1653, Fuensaldaña señalaba que "de dos años a esta parte quanto ha venido de España se ha dado al Partido", por lo que el peso de la guerra había recaído fundamentalmente sobre aquellas provincias ${ }^{72}$. El conde exageraba. Pero tampoco había sido escaso el dinero recibido por el Príncipe en Flandes, cuando, además, su principal vía de financiación era Burdeos ${ }^{73}$. Desde el 20 de junio de 1651 hasta el 30 de noviembre de 1653, los socorros enviados desde España ascendieron a 3.086.809 escudos, de los que se ingresaron 2.440.815. Durante el mismo período, la pagaduría general del ejército de Flandes entregó al Partido del Príncipe 750.769 escudos ${ }^{74}$.

Había que tratar de complacer, por todos los medios posibles, al Grand Condé, para que continuara la guerra civil. Hubo una concesión que particularmente dolió a Leopoldo-Guillermo. En marzo de 1653, informaba a Madrid de la visita que el Príncipe iba a hacer a Bruselas, donde pretendía ser tratado como un igual, con lo que el archiduque no podía estar de acuerdo, "conforme -decía- al decoro de nuestra Casa [de Austria] ni al grado en que vuestra majestad me tiene en estos países"75. Pero tuvo que ceder. Como le indicó Felipe IV, "en el estado presente de las cosas, pareze no sería prudencia romper y aventurar a romper con el Príncipe sobre materia tan vana"76. En el protocolo y la etiqueta no habría distinción entre el Gobernador General de Flandes y Condé.

A partir del verano de 1653, cuando su exilio se convirtió en un hecho, Luis II de Borbón se hará omnipresente y casi omnipotente en la política de Flandes. Tal circunstancia no será fácil de soportar para sus gobernantes, más aún cuando su injerencia crecía a la par que disminuía, en opinión del archiduque y Fuensaldaña, su valor como aliado. Los conflictos serán, por tanto, muy numerosos, de los que Condé tenderá a salir triunfante gracias al apoyo de la corte madrileña. Uno de los principales fue su financiación. Tras la caída de Burdeos, el Príncipe dependía de los socorros enviados a Flandes, incrementando la presión que ejercía, desde 1651, sobre la caja militar. Ya en octubre de 1653, Madrid aceptó la petición del archiduque y Fuensaldaña, para que las asistencias al Príncipe fueran separadas de las remesas del

\footnotetext{
71 AGS, Estado, leg. 2183, Leopoldo-Guillermo a Felipe IV, 16-VI-1653; Ibid., leg. 2083, exp. 20, Fuensaldaña a Leopoldo-Guillermo, 25-X-1654; AC, série P., vol. 14, f. 173, memoria de Condé a Fuensaldaña y respuesta de este, 29-V-1654 y 4-VI-1654.

72 AGS, Estado, leg. 2080, exp. 89, Fuensaldaña a Felipe IV, 6-X-1653.

73 Según informaba el barón de Watteville, el 24 de noviembre de 1652, desde septiembre del año anterior se había gastado en el frente meridional de la Fronda más de un millón de reales de a ocho, de los cuales, 550.000 se habían dado al Príncipe y 365.000 se habían empleado en la armada enviada a Burdeos. AGS, Estado, leg. 2079, exp. 241.

74 AGS, leg. 2186, socorros enviados desde España y dinero gastado con el Partido del Príncipe, 1651-1653; Maffi, En defensa del Imperio, pp. 307, 454.

75 AGS, Estado, leg. 2080, exp. 39, Leopoldo-Guillermo a Felipe IV, 29-III-1653.

76 Ibid., leg. 2264, Felipe IV a Leopoldo-Guillermo, ¿'-V-1653.
} 
ejército, sin dependencia de la pagaduría general ${ }^{77}$. Se hará a partir de 1654. Sin embargo, sus exigencias continuaron en Flandes. No en vano, lo que recibía desde España era insuficiente para mantener al Príncipe, sus tropas y clientela. Además, como recordaba Fuensaldaña, en abril de 1655, solo cumpliendo lo establecido en el tratado, en cada campaña, "se tiene obligación de darle un treyn de doze piezas de artillería y otro de 200 carros de bíberes, dos mil infantes y tres mil cavallos"78.

A finales de 1655 se vivió uno de los momentos más tensos. El 18 de diciembre, Condé se dirigía, bastante disgustado, a don Luis de Haro:

"Je viens d'apprendre encore par une lettre du comte de Fiesque que votre excellence envoie par deçà six cents mil éscus sans qu'il y en ayt rien pour moy. Je vous advoüe que cela ne m'a pas peu surpris et que je ne croyois pas debvoir estre oublié quand on envoie ainsy des sommes considérables pour les affaires de deçà"79.

En los mismos términos, volvía a escribirle el 15 de enero. Exigía participar en el reparto de los 600.000 escudos que se enviaban en letras ${ }^{80}$. Las órdenes de Madrid fueron claras: "que al conde de Fuensaldaña se le advierta mui especialmente que socorra al Príncipe de Condé quanto fuere posible"81. Pero no fue necesario. La presión realizada por el propio Condé en Flandes ya había dado sus frutos. El 1 de febrero, Fuensaldaña informaba que de dichas letras se había logrado, por vía de anticipación, el cobro de 200.000 escudos, de los que 29.600 se habían dado al Príncipe ${ }^{82}$.

El archiduque Leopoldo ponía sobre la mesa otra dificultad, en octubre de 1654. Condé estaba otorgando pasaportes a franceses para entrar y salir de los Países Bajos, apoyándose en los artículos X y XI del Tratado de Madrid. Sin embargo, decía:

"si el Príncipe dava pasaportes en la Guiena, donde solo él era dueño, no se sigue que haya de hazer lo mismo en estos estados, donde vuestra majestad se ha dignado de hazer elección de mi persona para governarlos; y si esto pasase así, afirmo a vuestra majestad, con toda claridad, que no podré responderle por la seguridad de ellos, siendo lo sumo de la regalía el dar pasaportes"83.

\footnotetext{
77 Ibid., leg. 2080, exp. 81, Junta de Estado, 25-X-1653 (se ven cartas de Leopoldo-Guillermo y de Fuensaldaña a Felipe IV y Luis de Haro, desde 11-IX-1653 hasta 2-X-1653).

78 Ibid., leg. 2084, exp. 169, Fuensaldaña a Luis de Haro, 27-IV-1655.

79 BNF, Département des manuscrits, Français 6731, f. 240, Condé a Luis de Haro, 18-XII1655.

80 AC, série P., vol. 16, f. 19, Condé a Luis de Haro, 15-I-1656.

81 AGS, Estado, leg. 2087, exp. 30 Consejo de Estado, 2-II-1656.

82 Ibid., exp. 70, Fuensaldaña a Felipe IV, 1-II-1656; Ibid., exp. 71, memoria de la distribución de los 200.000 escudos cobrados.

83 Ibid., leg. 2083, exp. 142, Leopoldo-Guillermo a Felipe IV, 31-X-1654.
} 
El asunto se trató en el Consejo de Estado, el 25 de noviembre. Fue entonces cuando el marqués de Valparaíso opinó de forma nada favorable sobre Condé, como hemos visto al comienzo de este artículo. El dar pasaportes era un hecho que no se podía permitir y que iba en notorio perjuicio del archiduque y de la autoridad de su gobierno. Pero Madrid no se atrevió a reprobárselo directamente al Príncipe, sino que determinó que don Luis de Haro hablara con sus representantes en la corte para que trataran de disuadirle ${ }^{84}$.

Condé no logró, en esta ocasión, el beneplácito de la corte madrileña. Sí lo tuvo, en cambio, para incrementar sus plazas en la frontera de los Países Bajos, algo fundamental para sus intereses, puesto que, desde 1652, estas no habían dejado de disminuir. Consiguió que se le entregase Rocroi, una vez conquistada, en 1653, y, al año siguiente, La Capelle y Le Catelet ${ }^{85}$. Pero Madrid no hizo más que confirmar lo que ya, ante las exigencias del Príncipe, había sucedido en Flandes. Sus autoridades le habían dado Rocroi, en compensación de lo que había perdido en las últimas campañas ${ }^{86}$, y las otras dos plazas, por su participación en el sitio de Arras, con el que se había pretendido, sin éxito, que los franceses abandonasen el de Stenay ${ }^{87}$.

Luis II de Borbón firmó acuerdos de buena vecindad y libre comercio con diversas plazas francesas en torno a Rocroi (Charlevile, Mont-Olimpe y Mézières), que no contaron con el beneplácito del archiduque ${ }^{88}$. Mayores problemas provocaron La Capelle y Le Catelet, puesto que su majestad dejaba de percibir una serie de contribuciones que debían pasar al Príncipe, para el mantenimiento de ambas guarniciones. Se llegó a un acuerdo para que, a cambio de aquellas, el Consejo de Finanzas le pagase una determinada cantidad los meses de verano. Ya en noviembre de 1655, Condé logró, en Madrid, que dichas asistencias se ampliasen al invierno ${ }^{89}$.

La obtención de estas plazas, en el transcurso de campañas militares, ya nos pone sobre aviso de la gran autoridad del Príncipe de Condé sobre el ejército de Flandes, aunque no formara parte, "de iure", de su cúpula militar.

${ }^{84}$ Ibid., exp. 142, Consejo de Estado, 25-XI-1654; Ibid., leg. 2265, Felipe IV a LeopoldoGuillermo, 2-XII-1654.

85 A las negociaciones de paz, en 1659, llegó sólo con tres plazas: Linchamp, Le Catelet y Rocroi (La Capelle había caído en 1656).

${ }^{86}$ AGS, Estado, leg. 2080, exp. 89, Fuensaldaña a Felipe IV, 6-X-1653; Ibid., exp. 81, Junta de Estado, 25-X-1653; Ibid., leg. 2264, Felipe IV a Condé, 29-X-1653.

87 Ibid., leg. 2083, exp. 119, Consejo de Estado, 7-X-1654; Ibid., leg. 2188, LeopoldoGuillermo a Felipe IV, 10-XII-1654.

${ }^{88} \mathrm{AC}$, série P., vol. 13, f. 418-419, artículos acordados entre el Príncipe de Condé, el duque de Noirmoutier y el caballero de Lamet, octubre 1653; Ibid., f. 488-489, memoria de LeopoldoGuillermo sobre el acuerdo anterior, sin fecha.

${ }^{89}$ AGS, Estado, leg. 2189, Fiesque a Felipe IV, 18-X-1655; Ibid., leg. 2085, exp. 129, Consejo de Estado, 6-XI-1655; Ibid., leg. 2266, exp. 222, Felipe IV a Leopoldo-Guillermo, 10-XI-1655; Ibid., leg. 2191, Leopoldo-Guillermo a Felipe IV, 29-XII-1655. 
Dos órdenes del rey católico, en mayo y julio de 1654, trataban de zanjar unos conflictos que, surgidos el año anterior, cuando por primera vez las tropas de Flandes y del Príncipe actuaron conjuntamente ${ }^{90}$, se habían agravado entonces $^{91}$. El 19 de mayo, Felipe IV escribía al archiduque Leopoldo:

"Conviene y encargo a vuestra alteza mucho que las operaciones de campaña se procuren resolver siempre de conformidad y que se atienda en ellas a los intereses del Príncipe [...]. Y también encargo a vuestra alteza que en el caso de ser atacada alguna de las plazas del Príncipe procure vuestra alteza socorrerla con mis armas, por todos los medios y caminos que según razón de guerra se pueden y deven intentar. $\mathrm{Y}$, asimismo, es mi voluntad e yntención que tanto en el mando de sus tropas como en las que se agregaren de las mías tenga absoluto poder y sin dependencia para la execución de aquellas operaciones que de común acuerdo se uvieren resuelto por vuestra alteza y su consejo"92.

De nuevo, Condé no había hecho más que exigir el cumplimiento del Tratado de Madrid (artículos XVIII-XX), suscrito en unas circunstancias muy diferentes. Ambos ejércitos debían actuar conjuntamente, por lo que la organización y desarrollo de las campañas militares debía negociarse con el Príncipe, quien luchaba por sus intereses, que no tenían por qué coincidir con los de la Monarquía Hispánica ${ }^{93}$. Asimismo, el ejército de su majestad debía acudir al socorro de sus plazas, en caso de ser atacadas por Luis XIV. Todo ello pese a que sus tropas nunca superaron los 15.000 hombres, de los cuales unos 5.000 eran proporcionados por el rey en cada campaña, frente a los 50.000-60.000 del ejército de Flandes ${ }^{94}$. Pero había más. Condé tenía el mando absoluto sobre sus soldados. Este hecho creaba un problema mayor, puesto que se negaba a estar en campaña bajo las órdenes del archiduque. Además, en el artículo XIX del tratado, negociado cuando se encontraba en la Guyena y no se planteaba la posibilidad de que ambos ejércitos se uniesen,

\footnotetext{
90 Ibid., leg. 2080, exp. 59, Leopoldo-Guillermo a Felipe IV, 28-VI-1653; Ibid., exp. 56, Junta de Estado, 15-VII-1653; Ibid., leg. 2264, Felipe IV a Leopoldo-Guillermo, 16-VII-1653.

91 Ibid., leg. 2265, memoria de Fiesque a Luis de Haro, 24-IV-1654; AC, série P., vol. 14, f. 142, Agustín Navarro a Lenet, 23-V-1654; Ibid., f. 152-156, Lenet a Agustín Navarro, 24-V1654; Ibid., f. 157, Agustín Navarro a Lenet, 27-V-1654; Ibid., f. 167-168, Lenet a Agustín Navarro, 27-V-1654.

92 AGS, Estado, leg. 2265, Felipe IV a Leopoldo-Guillermo, 19-V-1654.

${ }^{93}$ En las reuniones del alto mando del ejército de Flandes no solo participaba Condé, también su principal general Marsin, mariscal del campo de las tropas francesas desde 1645 (Béguin, Les princes de Condé, p. 428). Ya en 1652, Condé había logrado que Marsin, quien había abandonado el sitio de Barcelona para irse a la Guyena, fuera tratado como los mariscales de Francia por los generales de su majestad católica, en el caso de concurrir con ellos (AGS, Estado, leg. 2262, Felipe IV a Leopoldo-Guillermo, 24-II-1652). En Flandes, Marsin tenía lugar en las juntas y consejos después de Fuensaldaña y, por tanto, precedía al Maestro de Campo General (Ibid., leg. 2270, exp. 22, Felipe IV a don Juan, 11-II-1659).

94 Según la muestra general realizada el verano de 1657, en Flandes había 60.498 soldados, de los cuales 14.290 eran las tropas del Príncipe de Condé. AGS, Estado, leg. 2091, exp. 12, García Osorio (contador del ejército de Flandes) a Jerónimo de la Torre, 24-VI-1657.
} 
más allá de los hombres que se le debían entregar, se señalaba que "todas las dichas tropas de su majestad cathólica obedecerán al dicho señor Príncipe sin dificultad". ¿A quién le correspondía, entonces, la preeminencia y, por ende, el mando, en el campo de batalla?

El asunto nunca quedó completamente resuelto. En la conquista de Rocroi, cuando ya se escenificó el problema en plena operación militar, el archiduque había tenido que ceder, permitiendo una especie de igualdad con el Príncipe, cada uno al mando de sus tropas, lo que según Fuensaldaña había creado una gran confusión, "pues dos cavezas en un cuerpo es contranatural"95. La solución planteada por Felipe IV, en julio de 1654, no dejaba de ser ambigua. Según escribió al Príncipe de Condé:

"Devo decir que siempre que se me a preguntado sobre este punto del manejo del exército he entendido y respondido que al archiduque le asisten todas razones para la precedencia, por la representación que por tantos títulos y consideraciones hace de su persona. Lo mismo entiendo aora. Pero juntamente digo al archiduque que qualquier temperamento que tomare para vuestra satisfación me será muy agradable y de mucha estimación para mí. Y así devo esperar que le tomará, por su generosidad y por lo que siempre atiende a obligarme y a encaminar en todo quanto es de mi mayor servicio. Juntamente confío de vos que os portareis con tal discreción que el archiduque halle motivos nuevos para desear complaceros" ${ }^{\prime \prime 6}$.

En similares términos se dirigió al archiduque, aplaudiendo la resolución tomada en Rocroi, que podía ser el ejemplo a seguir ${ }^{97}$. En consecuencia, Leopoldo-Guillermo tendió a no participar en las campañas militares y a quedarse en Bruselas. En tales casos, era Fuensaldaña quien debía lidiar con el Príncipe, agravándose, si cabe, la situación, puesto que este exigía que estuviera bajo sus órdenes ${ }^{98}$.

Pero los conflictos no se reducían a las operaciones militares. ¿Cómo acuartelar las tropas de Condé después de cada campaña? En el invierno de 1651 sus hombres eran escasos, no más de $1.500^{99}$, y en el siguiente, el Príncipe todavía disponía de numerosas plazas en Francia y, además, optó por acuartelar buena parte de su ejército en Lieja, aunque sin el consentimiento del elector de Colonia ${ }^{100}$. Por tanto, las tropas alojadas en Flandes fueron reducidas ${ }^{101}$. Pero en noviembre de 1653 , Condé ya comenzó

95 AGS, Estado, leg. 2080, exp. 89, Fuensaldaña a Felipe IV, 6-X-1653.

96 Ibid., leg. 2265, Felipe IV a Condé, 3-VII-1654.

97 RAH, Colección Salazar y Castro, A-92, f. 236-238, Felipe IV a Leopoldo-Guillermo (sin fecha, pero julio de 1654).

98 AGS, Estado, leg. 2083, exp. 159, Consejo de Estado, 30-XII-1654.

${ }^{99}$ Ibid., leg. 2078, exp. 13, Junta de Estado, 17-II-1652.

100 Ibid., leg. 2080, exp. 17, Junta de Estado, 23-IV-1653.

101 Ibid., leg. 2186, socorros enviados desde España y dinero gastado con el Partido del Príncipe, 1651-1653. 
a exigir cuarteles para todo su ejército, amenazando con la ruptura del tratado. El problema fue trasladado a Madrid. Según las autoridades de Flandes, el estado de postración del país, después de tantos años de guerra, hacía imposible alojar los hombres del Príncipe y del duque de Lorena, que también lo exigía, puesto que a duras penas podía mantener al ejército de su majestad. La corte madrileña apoyó la decisión del archiduque y Fuensaldaña, por lo que Condé solo percibió una ayuda económica y tuvo, de nuevo, que alojar sus huestes en Lieja102. En esta ocasión, las quejas del elector de Colonia subieron de tono, obligando al archiduque a la firma de un tratado, para impedir la entrada de tropas en el Principado ${ }^{103 .}$

Lo acaecido el último invierno no podía repetirse. Ya en abril de 1654 , el conde de Fiesque, a la vez que planteaba cómo debía desarrollarse la campaña militar, con ambos ejércitos unidos, señalaba la obligación de, una vez terminada, dar cuarteles al Príncipe ${ }^{104}$. En agosto, solucionada la primera cuestión, Fiesque se centró en el alojamiento, apoyándose en el artículo XXII del tratado, por el cual las tropas de Condé debían ser recibidas en las tierras de su majestad, en caso de no poderse mantener en Francia ${ }^{105}$. De nada sirvieron las protestas del archiduque y Fuensaldaña, que, como las presiones del Príncipe, se repetirán al año siguiente. Por orden de Felipe IV, sus tropas tuvieron que ser acuarteladas en los Países Bajos, en el invierno de $1654^{106}$ y de $1655^{107}$

Como hemos comprobado, fueron constantes las quejas del archiduque y Fuensaldaña contra el Príncipe, elevadas a Madrid. Trataban de poner de manifiesto cómo su presencia era perniciosa. No solo presionaba y menoscaba la autoridad de los principales representantes de su majestad sino

102 Ibid., leg. 2083, exp. 139, Lenet a Fuensaldaña, 17-XI-1653; Ibid., exp. 140, LeopoldoGuillermo a Felipe IV, 18-XI-1653; Ibid., leg. 2080, exp. 91, Fuensaldaña a Luis de Haro, 29XI-1653; Ibid., exp. 90, Junta de Estado, 27-XII-1653; Ibid., leg. 2083, exp. 145, LeopoldoGuillermo a Felipe IV, 6-XII-1653; Henri Lonchay et al. (ed.), Correspondance de la cour d'Espagne sur les affaires des Pays-Bas au XVIIe siècle, vol. 4, (Bruselas: Maurie Lamertin, 1933), p. 436 (Leopoldo-Guillermo a Felipe IV, 20-XII-1653).

103 AGS, Estado, leg. 2083, exp. 30, Leopoldo-Guillermo a Felipe IV, 25-I-1654; Ibid., Consejo de Estado, 13-III-1654; Ibid., exp. 49, Leopoldo-Guillermo a Felipe IV, 21-III-1654; Ibid., Consejo de Estado, 16-IV-1654; "Tratado de neutralidad entre el señor archiduque de Austria Leopoldo Guillermo [...] y el señor Maximiliano Henrique, arzobispo, elector de Colonia y obispo y príncipe de Lieja [...] (Tirlemont, 17-III-1654), figura en de Abreu y Bertodano, Colección de los tratados de paz, pp. 233-261.

104 AGS, Estado, leg. 2265, memoria de Fiesque a Luis de Haro, 24-IV-1654.

105 Ibid., leg. 2083, exp. 110, memoria de Fiesque a Luis de Haro, 8-VIII-1654.

106 Ibid., Consejo de Estado, 6-IX-1654; Ibid., leg. 2265, Felipe IV a Leopoldo-Guillermo, 17IX-1654; Ibid., leg. 2083, exp. 117, Leopoldo-Guillermo a Felipe IV, 5-IX-1654; Ibid., Consejo de Estado, 2-X-1654; Ibid., leg. 2185, Leopoldo-Guillermo a Felipe IV, 27-X-1654, Ibid., leg. 2083, exp. 157, Consejo de Estado, 19-XII-1654; Ibid., leg. 2084, exp. 16, Leopoldo-Guillermo a Felipe IV, 10-XII-1654; Ibid., exp. 17, Fuensaldaña a Felipe IV, 10-XII-1654.

107 Ibid., leg. 2084, exp. 142, Condé a Luis de Haro, 24-III-1655; Ibid., exp. 141, Consejo de Estado, 7-V-1655; Ibid., exp. 140, Consejo de Estado, 21-V-1655; Ibid., leg. 2266, exp. 74, Felipe IV a Leopoldo-Guillermo, 30-V-1655; Ibid., 2085, exp. 171, Fuensaldaña a Felipe IV, 5XII-1655; BNF, Département des manuscrits, Français 6731, f. 224-225, Condé a Luis de Haro, 23-IV-1655; RAH, Colección Salazar y Castro, A-91, f. 50-51, Junta de Estado, 24-IX-1655; Ibid., f. 185-186, Felipe IV a Leopoldo-Guillermo (sin fecha, pero septiembre de 1655). 
que podía conllevar, incluso, la ruina de los Países Bajos. La obligación de acuartelar su ejército alimentó esta segunda vertiente de críticas. A partir del invierno de 1654, la indisciplina de sus hombres, que ya antes había sido denunciada cuando estaban en campaña ${ }^{108}$, se convirtió en uno de los principales argumentos contra el Príncipe. Aquellas provincias debían soportar el alojamiento de unas tropas que, además, se caracterizaban por su pillaje, incluso mayor que las del duque de Lorena, y contra el que nada podían hacer las autoridades de Flandes.

El archiduque Leopoldo, en enero de 1655, incidía en los desórdenes que causaban en las provincias de Güeldres, Henao y Luxemburgo, donde estaban alojadas y cuyos gobernadores habían acudido a mostrarle sus quejas, e incluso en Holanda y Lieja, hasta donde llegaban sus correrías ${ }^{109}$. Pero la corte madrileña se limitó a encargarle que "dé a entender al Príncipe de Condé, en la forma que mejor le pareciere, que reprima sus cavos y gente de los desórdenes que comete, siendo como son tan graves y perjudiciales y la ruina de aquellos países"110. Por su parte, Luis II de Borbón intentó defenderse de unas acusaciones que también eran esgrimidas para no darle cuarteles el invierno siguiente. "Je suis asseuré -escribía a don Luis de Haroque les trouppes de sa majesté et les lorrains ont fait mille fois plus de désordre que les miennes". Se trataba, en su opinión, de una información falsa que "ne peut estre d'autre gens que mes ennemis qui vous donnent de semblables avis pour me nuire auprès du roy et pour traverser ses bonnes intentions et les vostres"111.

No solo los soldados del Príncipe eran un problema, a causa de su indisciplina. Para poder acuartelar los ejércitos de su majestad, de Condé y de Lorena -hasta la definitiva deserción de sus tropas en 1655-, era necesario reformarlos, pero el Príncipe se negaba, para no perjudicar a sus principales seguidores, que estaban al frente de los regimientos ${ }^{112}$. El 29 de marzo de 1655, escribía el archiduque, que Condé no había reformado ni disciplinado sus tropas, "antes bien el número de los regimientos es grande y los excesos de su gente los mismos. Crece el Príncipe en recrutas y nuevas levas y hallándose dentro destos estados no es el menor de mis cuidados" ${ }^{\prime 13}$. Dos días después, insistía, en otra misiva, que mientras el ejército de Flandes disminuía, por falta de medios, el de Lorena y, sobre todo, el de Condé no hacían más que aumentar. El de este último, "con la comodidad de los

\footnotetext{
108 AGS, Estado, leg. 2080, exp. 89, Fuensaldaña a Felipe IV, 6-X-1653.

109 Ibid., leg. 2084, exp. 101, Leopoldo-Guillermo a Felipe IV, 16-I-1655; Ibid., exp. 102, el Gobenador de Güeldres a Leopoldo-Guillermo, 9-I-1655.

110 Ibid., exp. 100, Consejo de Estado, 5-III-1655.

111 BNF, Département des manuscrits, Français 6731, f. 224-225, Condé a Luis de Haro, 23IV-1655.

112 AGS, Estado, leg. 2185, Leopoldo-Guillermo a Felipe IV, 27-X-1654; Ibid., leg. 2085, exp. 171, Fuensaldaña a Felipe IV, 5-XI-1655.

113 Ibid., leg. 2084, exp. 136, Leopoldo-Guillermo a Felipe IV, 29-III-1655.
} 
quarteles que se le han dado y el dinero que puede sacar dellos y de los países vecinos por qualquier medios"114.

A largo de 1655, las autoridades de Flandes se empeñaron en demostrar el gran tamaño del ejército de Condé, hasta el punto de considerarlo prácticamente igual al de su majestad ${ }^{115}$. Unas cifras, sin duda, exageradas, como se puso de manifiesto en noviembre, cuando no hubo más remedio que volver a alojarlo ${ }^{116}$. Estas tropas suponían, a su juicio, un grave peligro para la seguridad de aquellas provincias, en el caso de rebelarse, en unos momentos en los que, además, no faltaban los rumores de acomodamiento del Príncipe con la corte francesa ${ }^{117}$.

El 9 de agosto de 1653, Leopoldo-Guillermo escribía a Felipe IV: "Malo será el Príncipe para enemigo, si se acordase con la Francia, y quedando firme en el Partido no dejará de ser cargoso, faltándole Burdeos y hallándose sin séquito en Francia"118. No es de extrañar que inmediatamente terminada la Fronda, el archiduque y Fuensaldaña insistieran a Madrid del difícil panorama que se presentaba, con el establecimiento de Condé, sus tropas y su clientela en los Países Bajos españoles, proponiendo limitar las asistencias e incluso romper el tratado ${ }^{119}$. Ya antes, en mayo, Fuensaldaña había planteado, como únicas posibilidades para su conservación, fijarle en la Guyena o en el Franco Condado, inclinándose por la primera opción, al igual que Madrid ${ }^{120}$. Sin embargo, no logró convencer al Príncipe ${ }^{121}$.

Tras la caída de Burdeos, su salida de Flandes fue constantemente propuesta por Leopoldo-Guillermo y Fuensaldaña. Esta solución no era mal

${ }^{114}$ Ibid., exp. 137, Lepoldo-Guillermo a Felipe IV, 31-III-1655.

115 Ibid., leg. 3860, Consejo de Estado, 3-I-1655 (dos cartas de Fuensaldaña a Luis de Haro, 5-XII-1654 y 12-XII-1654; las tropas de Condé se hallarían para la salida en campaña con 10.000 ó 12.000 hombres, las del duque de Lorena con 4.000 y las de su majestad con 10.300); Ibid., leg. 2085, exp. 32, Leopoldo-Guillermo a Felipe IV, 26-VI-1655 (las tropas del Príncipe, incluidas las que le proporcionaba su majestad, consistirían en 5.000 caballos y 3.400 infantes - propias serían 3.500 caballos y 2.500 infantes-, los loreneses en cerca de 3.000 caballos y 1.200 infantes, y el ejército de Flandes, 3.000 caballos y 5.000 infantes).

${ }^{116}$ Según la planta del ejército realizada en noviembre, para su alojamiento, las tropas de su majestad estaban formadas por 765 compañías de infantería y 257 de caballería; el ejército del Príncipe, por 120 compañías de infantería y 185 de caballería (sin incluir las tropas que le daba su majestad en cada campaña), y el del duque de Lorena, por 120 compañías de infantería y 105 de caballería. AGS, Estado, leg. 2085, exp. 174 (sin fecha, pero noviembre de 1655).

117 AGS, Estado, leg. 2189, Consejo de Estado, 17-VI-1655 (se ve una carta de LeopoldoGuillermo a Felipe IV, 10-VI-1655); Ibid., leg. 2085, exp. 172, Leopoldo-Guillermo a Felipe IV, $13-\mathrm{XI}-1655$.

118 Ibid., leg. 2080, exp. 66, Leopoldo-Guillermo a Felipe IV, 9-VIII-1653.

119 Ibid., exp. 69, Leopoldo-Guillermo a Felipe IV, 16-VIII-1653; Ibid., exp. 70, Fuensaldaña a Leopoldo-Guillermo, 11-VIII-1653; Ibid., exp. 63, Junta de Estado, 19-IX-1653 (se ven cartas de Leopoldo-Guillermo a Felipe IV, de 25-VII-1653, 8-VIII-1653, 9-VIII-1653 y 16 VIII-1653); Ibid., exp. 81, Junta de Estado, 25-X-1653 (se ven cartas de Leopoldo-Guillermo y Fuensaldaña a Felipe IV, desde 11-IX-1653 hasta 2-X-1653).

120 Ibid., leg. 2081, exp. 132, Fuensaldaña a Felipe IV, 16-V-1653; Ibid., exp. 129, Consejo de Estado, 11-VII-1653.

121 Ibid., leg. 2083, exp. 81, Consejo de Estado, 5-VII-1653 (se ve carta de Fuensaldaña a Luis de Haro, 13-VI-1653). 
vista por Madrid, dados los problemas que suscitaba Condé, aunque siempre que se lograra su beneplácito. En la segunda mitad de 1653, se volvió a plantear su marcha a la Guyena, para reactivar la rebelión, pero el Príncipe no mostró interés en hacerlo ${ }^{122}$. En la instrucción dada por el archiduque a Baltasar Mercader, en 1654, se planteaban tres opciones: proporcionarle los hombres y el dinero señalados en el tratado, para que se estableciera en torno a sus plazas en Francia y desde allí hiciera la guerra por separado, asentarlo en el Franco Condado o formar una armada para desembarcar en la Guyena. Tras la consulta de la Junta de Estado, Felipe IV se inclinó por la primera opción, en el caso de que hubiera medios de hacienda para llevarla a la práctica ${ }^{123}$. No se volvió a considerar esta posibilidad en Flandes, pero sí, nuevamente, ese mismo año, el que el Príncipe se trasladase a la Guyena, donde parecía resurgir la rebelión. El resultado fue el mismo que en las ocasiones anteriores: Condé no quiso ${ }^{124}$.

Fue en 1655 cuando más seriamente se trató en Madrid sobre su marcha, ante las insistentes quejas de las autoridades de Flandes. El 8 de abril, Fuensaldaña planteó a don Luis de Haro como mejor opción, para solucionar el problema del acuartelamiento del ejército del Príncipe, que el invierno siguiente se alojara en el Franco Condado y desde allí hiciera la guerra, por separado, en la Borgoña ${ }^{125}$. El asunto fue discutido en el Consejo de Estado, el 21 de mayo ${ }^{126}$. Junto con la propuesta de Fuensaldaña, se plantearon otras dos soluciones: extinguir las tropas del duque de Lorena, con lo que habría más comodidad para alojar las del Príncipe, y darle dinero para que acomodara la mayor parte de las tropas en sus plazas. Debía ser LeopoldoGuillermo, confiriéndolo con Fuensaldaña y otros ministros, quien eligiese "lo que se tuviere por más conveniente a mi servicio, seguridad y bien de estos países [...]. Y que en qualquiera destos medios [...] se atienda mucho a la satisfacción del Príncipe"127. En Flandes se optó por su marcha a la Borgoña española.

Parecía que, por fin, el archiduque y Fuensaldaña iban a poder librarse del Grand Condé. Pero todo se torció en el último momento. Tras la Junta de Estado celebrada el 24 de septiembre, Felipe IV escribía a LeopoldoGuillermo. No era conveniente el paso del ejército del Príncipe al Franco Condado ${ }^{128}$. Tanto se había insistido en su gran tamaño, tratando de alertar sobre su peligro, que el argumento se volvió contra las autoridades de Flandes. Tras la ocupación de los franceses de diversas plazas en el interior

122 Ibid., leg. 2080, exp. 81, Junta de Estado, 25-X-1653.

123 Ibid., leg. 2083, exp. 18, Junta de Estado, 18-II-1654; Ibid., leg. 2265, Felipe IV a Leopoldo-Guillermo, 22-II-1654.

124 Ibid., leg. 2083, exp. 81, Consejo de Estado, 5-VII-1654 (carta de Leopoldo-Guillermo a Felipe IV y de Fuensaldaña a Luis de Haro, 13-VI-1654).

125 Ibid., leg. 2084, exp. 143, Fuensaldaña a Luis de Haro, 8-IV-1655.

126 Ibid., leg. 2084, exp 140, Consejo de Estado, 21-V-1655.

127 Ibid., leg 2266, exp. 74, Felipe IV a Leopoldo-Guillermo, 30-V-1655.

128 RAH, Colección Salazar y Castro, A-91, f. 185-186, Felipe IV a Leopoldo-Guillermo (sin fecha, pero septiembre-octubre de 1655). 
de los Países Bajos, en la campaña de 1655, Madrid consideró contraproducente separar las tropas de Condé, que, dado su número, eran imprescindibles para su defensa. Como se había señalado en la Junta de Estado, "se estima por obra importantísima el apartar al Príncipe y excusar a aquellos pueblos la molestia insoportable de los quarteles, pero la regla es que vale más país arruinado que país perdido"129.

Por su parte, Condé, a través de sus agentes en Madrid, arremetía contra Fuensaldaña ${ }^{130}$. Atacar al archiduque, primo de Felipe IV y hermano del Emperador, no parecía una buena estrategia política y mucho menos criticar abiertamente al rey católico y su corte. Además, era con el conde, como Gobernador de las Armas, con quien principalmente debía relacionarse, en la organización y desarrollo de las campañas militares. Las quejas se iniciaron nada más producirse la pérdida de Burdeos. Fiesque había llegado a Madrid en mayo, pero, en un primer momento, le había comunicado a don Luis de Haro que su alteza estaba satisfecho de Fuensaldaña, porque, como informaba a Condé, "c'est sa créature"131. A partir de agosto, más concretamente del día 28, el Príncipe, aun a sabiendas de que formaba parte de la clientela del valido, ya dio instrucciones a su representante para comenzar el ataque contra Fuensaldaña ${ }^{132}$.

Se llevó a cabo una gran campaña de desprestigio contra don Luis Pérez de Vivero. Se le consideraba el culpable no solo de los males del Príncipe sino de los que aquejaban a la Monarquía Hispánica en aquellas provincias. Según indicaba Condé a Fiesque, en julio de 1655, y así lo debía transmitir, los problemas de Flandes eran por dos causas: la escasa asistencia que recibía de España y Fuensaldaña, a quien acusaba de poco coraje y falta de resolución ${ }^{133}$. El objetivo era claro. El 25 de abril de 1654, el Príncipe escribía a su "embajador":

"Quant au comte de Fuensaldagne, j'approuve de tous points la conduite que vous tenez pour son regard; et ne fault vous relascher en rien de ce que vous avez entrepris pour le faire retirer d'yci, car il n'y a poinct de jour que je n'aye quelque nouveau subjet de me plaindre de luy, et que luy mesme ne prenne à tasche de me faire quelque nouvelle pièce"134.

Al igual que el archiduque y Fuensaldaña trataban de lograr su salida de Flandes, esta era también la intención del Príncipe con respecto al segundo.

${ }^{129}$ Ibid., f. 50-51, Junta de Estado, 24-IX-1655.

${ }^{130}$ A través, sobre todo de la correspondencia activa y pasiva del Príncipe con Fiesque y sus demás representantes en Madrid, se observa la oposición contra Fuensaldaña. AC, série P., vol. 13-15 (1653-1655). Muchas de estas misivas figuran transcritas en duc d'Aumale, Histoire des princes de Condé, vol. 6, pp. 461-762.

${ }^{131}$ AC, série P., vol. 13, f. 164-167, Fiesque a Condé, 11/13-VI-1653.

132 British Library (BL), Add. Ms. 14007, f. 136-138, Condé a Fiesque, 28-VIII-1653.

${ }^{133}$ AC, série P., vol. 15, f. 239-240, Condé a Fiesque, 21-VII-1655.

${ }^{134}$ Ibid., vol. 14, f. 87-88, Condé a Fiesque, 25-IV-1654. 
Tras el fracaso de Arras, del que Fuensaldaña se convirtió en el chivo expiatorio, ya Madrid se planteó su destitución. Así informó, dándola por segura, Fiesque a Condé, quien no pudo por menos que mostrar una gran alegría $^{135}$. Se trató de un falso rumor. El Príncipe todavía tuvo que esperar unos meses para ver su deseo cumplido. Y con creces. Como hemos visto, no solo Fuensaldaña sino el propio Leopoldo-Guillermo fueron reemplazados en Flandes. El Grand Conde había ganado la partida.

\section{Don Juan, Caracena y Condé: una tensa calma}

Había que evitar que la situación política y militar en Flandes siguiera degradándose, por la falta de entendimiento entre los máximos representantes de Felipe IV y Condé. Los elegidos para tan ardua tarea fueron don Juan José de Austria, que se encontraba en uno de sus momentos de mayor popularidad, y el marqués de Caracena. Su llegada a Flandes se produjo en mayo de 1656. La corte madrileña había trabajado con gran esmero, tratando de allanar el camino para su buena correspondencia con el Príncipe francés.

El 20 de enero de 1656, don Luis de Haro escribía a Condé. Aunque daba por hecho que ya lo sabía, a través de sus representantes en Madrid, le informaba de la sustitución de Fuensaldaña. Por tanto, "cette résolution fait cesser le subiect d'en discourir et il y a seulement a souhaitter que le marquis [de Caracena] aye le bonheur de mériter vostre confiance et de vous donner toute la satisfaction que le roy désire et qu'il luy ordonnera fort particulièrement"136. El Príncipe no solo estaba informado sino tremendamente contento, como se lo transmitió al conde de Fiesque ${ }^{137}$. Su respuesta, al valido español, también dejaba traslucir su satisfacción, así como la voluntad de llevarse bien con el nuevo Gobernador de las Armas del ejército de Flandes:

"Quand à monsieur le marquis de Caracene, s'il vient icy comme vous me le mandez je vivray d'une manière avec luy que je suis assuré que sa majesté et votre excellence en serez satisfaits et que monsieur le marquis de Caracene ne le sera pas moins. J'espère que vous cognoistrez que s'il y a eu quelques fois de la difficulté entre monsieur le comte de Fuensaldagne et moy ce n'a esté que par le seul motif du service du roy et de l'interest du Party"138.

135 BL, Add. Ms. 14007, f. 158-159, Condé a Fiesque, 9-I-1655; Ibid., f. 160-161, Condé a Fiesque, 23-I-1655.

${ }^{136} \mathrm{AC}$, série P., vol. 16, f. 23-24, Luis de Haro a Condé, 20-I-1656.

137 Ibid., f. 57-59, Condé a Fiesque, 12-II-1656.

138 Ibid., f. 73, Condé a Luis de Haro, 19-II-1656. 
El conde de Fuensaldaña escribía a don Luis de Haro, el 25 de febrero. Ya se había corrido el rumor en los Países Bajos de la salida del archiduque Leopoldo y la llegada de don Juan. Por esta razón, había ido a hablar con el Grand Condé y a entregarle la carta que sobre esta materia le había escrito Felipe IV. "Estimó el Príncipe el fabor que su magestad le hacía y dixo que no deseava otra cosa que complacer y servir a su majestad. Que procuraría vivir con el señor don Juan con la atención y respeto que se devía a hixo de tan gran rey"139. Una nueva misiva fue enviada por Felipe IV a Condé, el 7 de marzo, con la confianza de que se alegraría de la ida de don Juan y que le ayudaría en el gobierno. Por su parte, el nuevo Gobernador y Capitán General tenía orden "para que vuestras cosas las trate y mire con la atención que es justo"140. Ese mismo día también don Juan José de Austria escribía al Príncipe, informándole muy cortésmente de su próxima llegada a Flandes y de su deseo de conocerle ${ }^{141}$.

Don Juan fue aleccionado sobre cómo debía ser su relación con Condé. Cuando se estaban elaborando las instrucciones que marcarían las directrices de su gobierno político y militar, el Consejo de Estado, en la reunión del 4 de marzo, ya consideró oportuno incluir una referencia explícita al Príncipe ${ }^{142}$. Así se hará tanto en la instrucción pública como en la reservada ${ }^{143}$. En la primera, figuraba lo siguiente:

"El Príncipe de Condé asiste en esos estados como aliado mío, con la infantería y cavallería francesa que sigue su Partido. En su persona concurren las muchas partes de valor y esperiencia en lo militar y político que abéis entendido. $Y$ en todo lo que hasta aora a sido empleado lo ha hecho con muy buen exemplo y con tal fineça $y$ aprobación que no se puede negar lo mucho que se le debe y lo obligado que me tiene. Encargoos tengáis con él muy buena correspondencia, comunicándole en confiança aquellas cosas que juzgáredes combenir para el mayor acierto dellas, haciéndole todos los gustos que se pueda y en que no se incurra en incombenientes. Que con esta calidad holgaré que dispongais y encaminéis todo lo que pueda facilitar más la confianza y amistad entre los dos".

El valido comunicó a don Juan el envío de tales instrucciones, a la vez que insistió en algunos de sus puntos, entre ellos el referente a Condé. Lo transcribimos, a continuación, como testimonio, además, de la alta estima de don Luis de Haro hacia este personaje:

\footnotetext{
139 AGS, Estado, leg. 2087, exp. 80, Fuensaldaña a Luis de Haro, 25-II-1656.

140 Ibid., leg. 2267, exp. 100, Felipe IV a Condé, 7-III-1653.

${ }^{141}$ AC, série P., vol. 16, f. 99, don Juan a Condé, 7-III-1656.

142 AHN, Estado, leg. 1414, Consejo de Estado, 4-III-1656.

143 Ambas figuran en AHN, Estado, leg. 1414.
} 
"Con el Príncipe de Condé combendrá yncreyblemente que vuestra alteza trate con gran confianza y amistad, procurando que él lo reconozca así y que se halle de vuestra alteza con toda satisfación porque es un príncipe de mucho espíritu y valor, gran soldado y que antepone su honor a todas las demás cosas del mundo, como se reconoze en la gran constancia y fineça con que a perseverado en el Partido y servicio de su magestad, haviendo hecho después que entró en él tantas pérdidas propias, como se save, y su magestad tantas ganancias. Por donde se reconoze la obligación que su magestad tiene de mostrarle toda gratitud y continualle su protección hasta yncluylle en la paz, con todas ventajas suyas. Por cuyas razones combiene mucho que vuestra alteza procure obligarle por todos quantos caminos se pueda y asegurarle desto mismo, que creo será muy fácil y que no abrá cosa que pueda embaraçar esta buena correspondencia y amistad entre vuestra alteza y él, por quanto el tratamiento abrá de ser ygual en todo como le tenía con el señor archiduque"144.

Don Luis de Haro hacía referencia al protocolo, así en las cortesías y actos públicos, como en el mando en el ejército, que debía regir entre ambos. Había sido una cuestión delicada, aunque no porque don Juan pusiera alguna resistencia, como había hecho Leopoldo-Guillermo. Parecía que el Príncipe no estaba dispuesto a tratarlo con igualdad, debido a su condición de bastardo $^{145}$. Fuensaldaña fue el encargado de hablar con él, para informarle "que don Juan tiene orden, como ya se le ha dicho, de correr con él en toda buena correspondencia e iguales en las cortesías, pero debajo de presupuesto de que no se podría pasar ni pasará por otra cosa"146. Felipe IV no iba a transigir en este aspecto y así lo entendió Condé.

No obstante, la obsesión de don Juan por la etiqueta y un cierto sentimiento de inferioridad hacia Luis II de Borbón, debido a su origen ilegítimo, hábilmente explotado por este último, sí parece haber sido una de las razones del pronto distanciamiento entre ambos ${ }^{147}$. Además, en este aspecto, Condé logró una nueva concesión por parte de Felipe IV. En mayo de 1657, don Juan de Austria señalaba que el Príncipe quería que tanto él como el marqués de Caracena visitasen a su hijo, el duque de Enghien, y le diesen el mismo tratamiento que a su padre. Por el momento se había excusado, señalando que necesitaba conocer el parecer de su majestad ${ }^{148}$. No solo la corte madrileña determinó satisfacer a Condé, sino también pedirle disculpas, a través del conde de Fiesque, por no haber realizado don Juan todavía esta visita $^{149}$.

\footnotetext{
144 RAH, Colección Salazar y Castro, A-91, f. 56, Luis de Haro a don Juan (sin fecha).

145 AGS, Estado, leg. 2087, exp. 80, Fuensaldaña a Luis de Haro, 25-II-1656.

146 Ibid., exp. 73, Consejo de Estado, 5-IV-1656.

147 Insisten en este hecho: Castilla Soto, Don Juan José de Austria, p. 127; Calvo Poyato, Juan José de Austria, p. 75; Ruiz Rodríguez, Don Juan José de Austria, pp. 192-193.

148 AGS, Estado, leg. 2090, exp. 63, don Juan a Felipe IV, 11-V-1657.

149 Ibid., exp. 76, Consejo de Estado, 13-VI-1657.
} 
El contraste con la etapa anterior fue notorio. Madrid ya no tuvo que intervenir por problemas en el reparto de las asistencias, los cuarteles de invierno, que Condé siguió disfrutando en los Países Bajos, la organización y desarrollo de las campañas militares, en las que ahora el Príncipe y don Juan actuaban conjuntamente... El único conflicto que llegó al monarca, en 1657, fue en relación a lo que aquellas provincias, a través del Consejo de Finanzas, debían pagar a Condé: 234.000 florines anuales, para el mantenimiento de las guarniciones de La Capelle y Le Catelet (12.000 florines cada mes), el equipaje de invierno del Príncipe (60.000 florines al año), la pensión de su general Marsin (60.000) y de Lenet (30.000). No solo el Príncipe exigía con gran violencia, en palabras de don Juan, que se le continuara dando la consignación de La Capelle, pese a haberla perdido en manos de los franceses (en 1656), sino que, en su opinión, aquellas provincias ya no podían contribuir con tales cantidades ${ }^{150}$. La solución de Madrid fue seguir abonándoselo, en compensación de las asistencias que se estaban debiendo al Príncipe, y que el montante total se pagase desde España, en rentas situadas en estos reinos o consignadas en las provisiones del ejército que se enviaban a Flandes ${ }^{151}$.

Aunque el momento más crítico tuvo lugar por un motivo muy diferente. A finales de 1657, Condé cayó gravemente enfermo. ¿Qué sucedería con sus tropas y sus plazas en el caso de morir? El Príncipe había manifestado la intención de que Marsin quedara al frente de ellas y no se llegara a ningún acuerdo con la corte francesa sin contar antes con el beneplácito de su majestad católica. Pero no todos los oficiales de su ejército parecían dispuestos a obedecer a este general. Don Juan, muy preocupado, solicitó instrucciones a Madrid ${ }^{152}$. Tras la consulta del Consejo de Estado, la orden de Felipe IV fue tratar de mantener satisfechos y con mucha confianza a Marsin y los demás dependientes del Príncipe. Había que esperar cómo se desarrollaban los acontecimientos ${ }^{153}$. Por fortuna, Condé recobró la salud.

Don Juan y Caracena asumieron que había que contar con el Príncipe. Su poder ya estaba consolidado y era incontestable. Esto no significaba, sin embargo, que los problemas de la época del archiduque y Fuensaldaña hubieran desaparecido completamente. Así, en diciembre de 1657, don Juan de Austria, Caracena y don Alonso de Cárdenas se reunieron, para tratar la difícil situación de la Monarquía y de Flandes en particular, cuyas reflexiones serán enviadas a Madrid. Esta Junta llegó a la conclusión de la imposibilidad de hacer la guerra al año siguiente. El principal problema era, en su opinión, la falta de asistencias desde España. Pero también se planteaban otros, como la presencia de Condé. No ponían en duda su buen servicio militar, pero

150 Ibid., leg. 2091, exp. 78, don Juan a Felipe IV, 26-IX-1657; Ibid., leg. 2088, exp. 187, Consejo de Estado, 16-XII-1657.

${ }^{151}$ Ibid., leg. 2269, exp. 22, Felipe IV a don Juan, 29-I-1658.

152 Ibid., leg. 2093, exp. 19, don Juan a Felipe IV, 14-XII-1657.

153 Ibid., exp. 18, Consejo de Estado, 16-I-1658; Ibid., leg. 2269, exp. 21, Felipe IV a don Juan, 29-I-1658. 
continuaban los desórdenes de sus soldados, tanto en campaña como en los cuarteles de invierno, que eran imitados por las tropas de su majestad. A ello se unía el nuevo riesgo para la seguridad que se había planteado recientemente, si Luis II de Borbón llegara a fallecer ${ }^{154}$.

Ya hemos visto, en la instrucción de Condé a Lenet, en mayo de 1658, cuál era la opinión que debía ofrecer en la corte madrileña sobre don Alonso de Cárdenas. Veamos el parecer del Príncipe sobre los dos máximos representantes del rey en aquellas provincias.

"Pour monsieur de Caracene, faut parler en bien de sa manière d'agir à la guerre et dans les affaires, et comme estant de mes amis, et faire considérer aussi ce à quoy il se porte pour n'avoir pas monsieur don Juan por ennemy, croyant peut-estre qu'il pourroit ruiner et retarder les affaires de sa maison, ainsy qu'il seroit à propos de le satisfaire sur ce point, en sorte qu'il n'eust plus rien à mesnager avec luy, et ensuitte augmenter son authorité pour faire marcher les affaires d'un meilleur air. Sera bon faire savoir comme le peu de concert cause de mauvaises résolutions à la guerre, comme I'an passé, qui après deviennent irrémédiables"155.

Dos cosas quedaban claras. La primera, la buena correspondencia entre Condé y Caracena. Se entretejió una estrecha alianza que también, contribuyó, y mucho, al fortalecimiento de la posición del Príncipe en Flandes ${ }^{156}$. Y eso que no era fácil tratar con él. Era considerado por sus contemporáneos como un hombre irascible, impetuoso y libertino. Como señalará Caracena, ya nombrado Gobernador y Capitán General, era "persona que disgustado una vez con un ministro por qualquiera cosa no se satisface, aunque en otras muchas se le dé satisfacción"157. En segundo lugar, se ponía de manifiesto la mala relación entre Caracena y don Juan. Una situación en la que Condé apoyaba, muy hábilmente, al primero ${ }^{158}$. En cuanto al bastardo regio, la instrucción a Lenet resulta bastante más confusa:

"Il faut se souvenir de son caractère, comme il est de sa personne, de sa manière d'agir, de celle dont il est dans l'esprit du général et du particulier, comme il se conduit à la guerre, en particulier et dans sa

\footnotetext{
154 Ibid., leg. 2093, exp. 59, Junta celebrada por don Juan, Caracena y Alonso de Cárdenas (enviada a Madrid con carta de don Juan a Felipe IV, 19-I-1658).

155 Lenet, Mémoires, p. 626.

156 Incluso, en la instrucción de Condé a Pierre Lenet, en mayo de 1658 , se le indicaba que fuera a visitar a los padres y amigos de Caracena, "pour sçavoir d'eux en quoy on le peut servir". Lenet, Mémoires, p. 627.

157 AGS, Estado, leg. 2094, exp. 89, Caracena a Felipe IV, 28-XII-1658.

158 Ruiz Rodríguez, Don Juan José de Austria, p. 189; Benavides, Milicia y diplomacia, pp. 523535.
} 
maison; faut savoir de monsieur le comte de Fiesque comment il en aura parlé pour ne se pas [en blanco] "159.

¿Qué debía contar de don Juan y cómo debía hacerlo? Vista la opinión sobre Caracena no es difícil intuir que la que tenía sobre el Gobernador y Capitán General de Flandes era muy distinta. La relación entre ambos había comenzado bien. Pero el 25 de octubre de 1656, escribía Barrionuevo: "pidió el Príncipe de Condé al señor don Juan de Austria 3.000 hombres para ir a socorrer la Capela y no se los dio, de que se ha disgustado en extremo, y se teme que desde aquí adelante no han de correr bien"160. Fue al año siguiente, tras los diversos fracasos de la campaña militar, cuando el enfrentamiento ya era un hecho. Y de dominio público, hasta el punto que llegó a los oídos de Mazarino ${ }^{161}$. Don Juan nunca se quejó del Príncipe a la corte madrileña, quizás a sabiendas de que no le faltaban enemigos en ella. Sí lo hizo Condé, posiblemente por lo mismo, de lo que era informado por sus agentes en Madrid. Eso sí, las críticas sobre don Juan siempre fueron en un tono muy diferente a las de Fuensaldaña, puesto que se trataba, aunque bastardo, del hijo de Felipe IV. De esta forma, el 11 de octubre de 1657, escribía al conde de Fiesque:

"Don Juan est un homme sans action, négligeant au dernier point, et ne bougeant presque pas de son lit [...]. Ce ne serait pas trop grave [...] si don Juan ne venait pas à l'armée, mais il se pique d'y venir et il agit si peu, si à contre-temps et avec tant d'irrésolution que cela fait manquer toutes les affaires".

Fiesque debía transmitirlo a don Luis de Haro "les plus délicatement que vous pourrez" y únicamente "pour le motif du zèle que j'ai pris pour le service de sa majesté"162. La forma era distinta, más sutil, pero las quejas del Príncipe tuvieron gran efecto en la corte madrileña. El 14 de noviembre de 1657, Barrionuevo apuntaba que el conde de Fiesque tenía cartas "de los muchos gastos exorbitantes del señor don Juan de Austria, en que gasta cada día más de 3.000 ducados $[\ldots]$, con que no hay hacienda en el mundo para su liberalidad"163. Una semana después, escribía: "dícese traen sin duda al señor don Juan de Austria a España, y muy presto, y que en aquellos países quedarán solos el Príncipe de Condé y el marqués de Caracena, para evitar gastos y excusar inconvenientes" ${ }^{\prime 164}$.

Esta mala relación fue explotada en Madrid por los detractores de don Juan. Por ende, su "leyenda negra" correrá pareja a la "leyenda rosa" de Condé.

\footnotetext{
159 Lenet, Mémoires, p. 626. También figura incompleto en BNF, Département des manuscrits, Français 6731, f. 275.

160 De Barrionuevo, Avisos, vol. 3, p. 48 (25-X-1657).

161 Calvo Poyato, Juan José de Austria, p. 77.

162 Cit. por Pujo, Le Grand Condé, p. 243.

163 De Barrionuevo, Avisos, vol. 3, p. 368 (14-XI-1657).

164 Idem, p. 376 (21-XI-1657).
} 
Solo es necesario detenerse en las acusaciones vertidas sobre el primero y su gobierno en Flandes, en las Memorias inéditas del Padre Nithard, realizadas por un ferviente defensor del jesuita ya durante su exilio en Roma:

"Dejándose al principio governar de la destreza y experienzia del Príncipe de Conde y el marqués de Carazena salió lucidamente del empeño de socorrer a Valencianas [...]. Estando en Flandes dio muchas muestras de su rara ambición y ánimo altivo [...]; limaba las atentas instrucciones dadas por el Consejo de Estado de cómo se havía de portar con el Príncipe de Condé, y le meditaba desaires que, frustrados de los sublimes espíritus de aquel Príncipe, caían sobre su familia como el diente venenoso de la vívora que no pudiendo herir al hombre da en la piedra [...]. Y finalmente se portaba con tanta pompa, fausto y magestad como quien lo quería ser; y por esto el de Condé le llamaba don Juanísimo".

Don Juan José de Austria era, por tanto, el único culpable de la derrota de las Dunas (14 de junio de 1658),

"no esperando como prudentemente le aconsejaban dos tan grandes cabezas como el Príncipe de Condé y marqués de Carazena a que llegase la artillería y se agregasen todas las tropas para desalojar al de Turena, el qual, reconociéndole inferior y desprevenido, le salió al enquentro y le rompió con tan lastimoso estrago de nuestro exército que allí murieron las esperanzas de defender los Países Bajos"165.

Esta es también la visión clásica de la batalla de las Dunas, alimentada por la historiografía francesa desde el siglo XIX, empeñada en exaltar al ejército de Luis XIV y, también, mantener incólume la gloria del Príncipe de Condé. Aunque en la actualidad comienza a ser desterrada. No solo la derrota era inevitable, ante un ejército mayor en número y reforzado por tropas inglesas, sino que, además, ¿cómo responsabilizar únicamente a don Juan de la decisión, habida cuenta de la autoridad que gozaba Condé en las operaciones del ejército de Flandes? ${ }^{166}$

El 13 de noviembre de 1658, Felipe IV firmaba el nombramiento como Gobernador y Capitán General de Flandes, en ínterin, de don Luis de Benavides Carrillo ${ }^{167}$. Condé y Caracena veían cumplido su deseo de apartar a don Juan de los Países Bajos ${ }^{168}$. Ese mismo día, el monarca escribía a ambos. Las prevenciones de 1656 volvían a repetirse. Insistía al marqués en

165 Biblioteca Nacional de España, Mss. 8344, f. 31-33.

166 Inglis-Jones, "The Battle of the Dunes...", pp. 249-277.

167 AHN, Estado, leg. 1414.

168 El hijo bastardo de Felipe IV abandonó Flandes, camino de la guerra de Portugal, en marzo de 1659. 
que debía procurar, tener "satisfecho y confiado al Príncipe de Condé"169. De la misma manera, esperaba, como señalaba a don Luis II de Borbón, que,

"os será muy gustoso y grato el nombramiento de dicho marqués, por la buena correspondencia que con él haveis conservado, la qual le he encargado y mandado continuar de su parte, como espero que también lo haréis de la vuestra, pues interesan tanto en ello nuestras combeniencias y los sucesos de las armas"170.

En términos generales, se mantuvo la buena sintonía entre Caracena y Condé. De esta forma, ambos fueron juntos a pacificar la ciudad de Amberes, en octubre de $1659^{171}$. Sin embargo, algunos indicios invitan a pensar que la relación ya no era tan estrecha como antes, cuando habían unido sus fuerzas frente a don Juan. Quizás solo el que el último año de la guerra FrancoEspañola estuviera presidido por las conversaciones de paz y la firma de esta impidió la ruptura.

La delicada situación en los Países Bajos meridionales, tras la desastrosa campaña de 1658, obligaba a reducir los gastos militares. Había que reformar las tropas para su acomodamiento en los cuarteles de invierno. Sin ningún eco en Madrid, ya don Juan, en enero de 1658, había sugerido la necesidad de que además del ejército de su majestad, Condé reformase el suyo, aunque, añadía, siempre se negaría ${ }^{172}$. Caracena insistió en ello, como en tiempos del archiduque y Fuensaldaña. No lo consiguió en el invierno de $1658^{173}$. Ya en mayo de 1659 , volvió a señalar a Felipe IV el grave problema que se plantearía ese invierno. Si continuaba la guerra y el Príncipe no reformaba sus tropas, "será ympusible [...] que puedan estas provincias alojar más en ellas el exército, porque totalmente están destruydas y ymposibilitadas de medios con que asistirle en los alojamientos, faltando también pays en que ponerle"174. En la Junta de Estado, celebrada el 14 de junio, se determinó que Caracena informase de la forma en que se podría llevar a cabo dicha reforma, sin molestar a Condé ${ }^{175}$. Así lo hizo, aunque ya para entonces se había firmado el Tratado de los Pirineos ${ }^{176}$.

También resurgió otro problema, que parecía olvidado, el del mando del ejército. Don Juan no había tenido reparo en participar junto al Príncipe

169 AGS, Estado, leg. 2094, exp. 3, Felipe IV a Caracena, 13-XI-1658.

170 Ibid., exp. 4, Felipe IV a Condé, 13-XI-1658.

${ }^{171}$ BNF, Département des manuscrits, Français 6731, f. 295-298, Relación de todo lo sucedido en la villa de Amberes en la sublevación del pueblo, este presente año de 1659 (impreso). Sobre el movimiento de protesta de la ciudad de Amberes, que tuvo su máxima expresión a partir de 1655, así como su solución, por la vía pactista, tras el motín popular acaecido el 8 de agosto de 1659, vid. Manuel Herrero Sánchez, El acercamiento hispano-neerlandés (16481678), (Madrid: CSIC, 2000), pp. 206-213.

172 AGS, Estado, leg. 2195, don Juan a Felipe IV, 19-I-1658.

173 Ibid., leg. 2094, exp. 89, Caracena a Felipe IV, 28-XII-1658.

174 Ibid., leg. 2197, Caracena a Felipe IV, 7-V-1659.

175 Ibid., leg. 2094, exp. 176, Consejo de Estado, 14-VI-1659.

176 Ibid., leg. 2095, exp. 95, Caracena a Felipe IV, 8-XI-1659. 
francés en las campañas militares, siguiendo la práctica inaugurada, aunque a regañadientes, por Leopoldo-Guillermo en Rocroi. Fue Condé el que se negaba a concurrir de esta forma, con Caracena, quien ya no era miembro de la casa de Austria. El 20 de enero de 1659, Lenet, ahora principal representante del Príncipe en la corte madrileña, exigía, en su nombre, "se sirva su majestad dar las órdenes precisas y dezir en qué forma y cómo el Príncipe ha de mandar las tropas de su majestad, conforme a su tratado y como se debe a su sangre y cualidad". Consideraba que era a este a quien debía corresponder el mando, no solo de sus hombres sino también del ejército de Flandes. Planteaba dos posibilidades. Por un lado, un mando absoluto, nombrándolo Felipe IV "generalísimo de los exércitos". Un título que, señalaba, "no lo pretende su alteza ny tampoco me dize que lo reúsa sino que dexa con todo rendimiento a la voluntad del rey lo que mejor pareciere a su magestad de más utilidad a los intereses de sus estados". Por otro, "un mando de honor y de respeto, que se debe a un príncipe de sangre real de los muchos servicios y experiencia del Príncipe, mi señor"177.

La decisión no fue fácil de tomar y se demoró hasta el 11 de febrero ${ }^{178}$. Si bien la desconocemos, debió de ser favorable, de alguna manera, a Condé. Felipe IV escribía al marqués de Caracena y al Príncipe, el 25 de marzo. Al primero señalaba que, por carta del día 13, le había enviado la forma en que tenía que gobernarse con el Grand Condé179. A este último le indicaba que "en lo que monsieur de Lenet me representó de vuestra parte, he resuelto lo que entenderéis del marqués de Carazena, a que me remito, deseando que os hallaréis en todo muy satisfecho"180. Pero, el 7 de mayo, Caracena señalaba al rey que todavía no había recibido la primera misiva ${ }^{181}$. De todas formas y, por suerte para el Gobernador y Capitán General, aquel año ya no hubo campaña militar en Flandes, pues las negociaciones de paz ya estaban en marcha.

Luis II de Borbón abandonó definitivamente los Países Bajos meridionales, el 29 de diciembre de 1659, tras la firma del Tratado de los Pirineos, que le permitía reconciliarse con Luis XIV ${ }^{182}$. Habían terminado ocho años en los que, como hemos comprobado, aquellas provincias vivieron una suerte de "gobierno extraordinario". Las principales instituciones y ministros de su majestad católica tuvieron que compartir protagonismo con el Grand Condé, personaje ajeno a la estructura político-militar de la Monarquía Hispánica, que, sin embargo, gozaba del apoyo de Felipe IV y de su valido.

177 Ibid., leg. 2094, exp. 126, Lenet a Fernando de Contreras (para entregar a Felipe IV), 20I-1659.

178 Se menciona en AGS, Estado, leg. 2197, Consejo de Estado, 4-III-1659.

179 Ibid., leg. 2270, exp. 30, Felipe IV a Caracena, 25-III-1659.

180 Ibid., exp. 59, Felipe IV a Condé, 25-III-1659.

181 Ibid., leg. 2197, Caracena a Felipe IV, 7-V-1659.

182 Vid. Daniel Séré, La Paix des Pyrénées. Vingt-quatre ans de négociations entre la France et I'Espagne (1635-1659), (Paris: Honoré Champion, 2007). 
Bibliografía:

Abreu y Bertodano 1749: Joseph Antonio de Abreu y Bertodano, Colección de los tratados de paz [...]. Reinado de Phelipe IV. Parte IV, (Madrid: Por Antonio Marín, Juan de Zúñiga y la viuda de Peralta, 1749).

Arlette 1989: Jouanna Arlette, Le devoir de révolte. La noblesse française et la gestation de l'État moderne, 1559-1661, (París: Fayard, 1989).

Aumale 1892, 1896: Henry d'Orléans, duc d'Aumale, Histoire des princes de Condé aux XVe et XVIIe siècles, vol. 6, 7, (París: Calmann Lévy, 1892, 1896).

Baelde y Vermeir 1995: Michel Baelde y René Vermeir, "Conseil d'État", en Les Institutions du Gouvernement Central des Pays-Bas Habsbourgeois (1482-1795), ed. E. Aerts et al., vol. 1, (Bruselas: Archives Générales du Royaume, 1995), pp. 257-274.

Barrionuevo 1892, 1893: Jerónimo de Barrionuevo, Avisos, vol. 1-4, (Madrid: Imprenta y Fundición de M. Tello, 1892, 1893).

Béguin 1999: Katia Béguin, Les princes de Condé. Rebelles, courtisans et mécènes dans la France du Grand Siècle, (Seyssel: Champ Vallon, 1999).

Benavides 2012: José I. Benavides, Milicia y diplomacia en el reinado de Felipe IV. El marqués de Caracena, (Astorga: Akrón, 2012).

Bertière 2011: Simone Bertière, Condé, le héros fourvoyé, (París: Éditions de Fallois, 2011).

Brunet y Ruiz Ibáñez 2015: Serge Brunet y José Javier Ruiz Ibáñez, "Los exilios franceses en la Monarquía Hispánica", en Los exiliados del rey de España, coord. José Javier Ruiz Ibáñez e Igor Pérez Tostado, (Madrid: Fondo de Cultura Económica, 2015), pp. 131-159.

Calvo Poyato 2002: José Calvo Poyato, Juan José de Austria. Un bastardo regio, (Barcelona: Plaza \& Janés, 2002).

Cárdenas 2011: Alonso de Cárdenas, La revolución inglesa (1638-1656), ed. Ángel Alloza y Glyn Redworth, (Madrid: Biblioteca Nueva, 2011).

Castilla Soto 1989: Josefina Castilla Soto, "Las relaciones entre Felipe IV y Carlos II de Inglaterra, durante el protectorado de Cromwell (1656-1659)", Espacio, Tiempo y Forma, Serie IV, Historia Moderna, 2, (1989), pp. 111124.

Castilla Soto 1992: Josefina Castilla Soto, Don Juan José de Austria (hijo bastardo de Felipe IV): Su labor política y militar, (Madrid: UNED, 1992).

Chapman 1964: Hester W. Chapman, The Tragedy of Charles II in the Years 1630-1660, (Londres: J. Caspe, 1964). 
Constant 2016: Jean-Marie Constant, C'était la Fronde, (París: Flammarion, 2016).

Coppens 1995: Hernam Coppens, "Conseil des Finances", en Les Institutions du Gouvernement Central des Pays-Bas Habsbourgeois (1482-1795), ed. E. Aerts et al., vol. 2 (Bruselas: Archives Générales du Royaume, 1995), pp. 497-521.

De Schepper 1995: Hugo de Schepper, "Conseil Privé", en Les Institutions du Gouvernement Central des Pays-Bas Habsbourgeois (1482-1795), ed. E. Aerts et al., vol. 1, (Bruselas: Archives Générales du Royaume, 1995), pp. 287-317.

De Schepper y Vermeir 1995: Hugo de Schepper y René Vermeir, "Gouverneur-Général", en Les Institutions du Gouvernement Central des Pays-Bas Habsbourgeois (1482-1795), ed. E. Aerts et al., vol. 1, (Bruselas: Archives Générales du Royaume, 1995), pp. 187-208.

Esteban Estríngana 1998: Alicia Esteban Estríngana, "La crise politique de 1629-1633 et le début de la prééminence institutionnelle de Pierre Roose dans le gouvernement général des Pays-Bas Catholiques", Belgisch Tijdschrift voor Filologie en Geschiedenis, 76, (1998), pp. 939-977.

Esteban Estríngana 2001: Alicia Esteban Estríngana, "El 'gobierno de los príncipes' en los Países Bajos católicos. La sucesión del cardenal-infante al frente de las provincias obedientes (1641-1644)", Anali di Storia moderna e contemporanea, 7, (2001), pp. 166-222.

Esteban Estríngana 2002: Alicia Esteban Estríngana, Guerra y finanzas en los Países Bajos católicos: de Farnesio a Spinola (1592-1630), (Madrid: Ediciones del Laberinto, 2002).

Esteban Estríngana 2005: Alicia Esteban Estríngana, Madrid y Bruselas. Relaciones de gobierno en la etapa postarchiducal (1621-1634), (Leuven: Leuven University Press, 2005).

Esteban Estríngana 2013: Alicia Esteban Estríngana, "El control y la fiscalización del gasto militar", en Historia militar de España: Edad Moderna. Escenario europeo, coord. Luis Ribot, (Madrid: Ministerio de Defensa, 2013), pp. 259-284.

Esteban Estríngana y Ruiz Ibáñez 1998: Alicia Esteban Estríngana y José Javier Ruiz Ibáñez, "El gobierno político y militar de los Países Bajos. La gestión administrativa e institucional de un territorio "periférico" de la Monarquía Católica (siglos XVI-XVII)", Relaciones, 19, 73, (1998), pp. 115167.

Fulaine 1997: Jean-Charles Fulaine, Le Duc Charles IV de Lorraine et son armée, 1624-1675, (Metz: Editions Serpenoise, 1997). 
González de León 2009: Fernando González de León, The Road to Rocroi. Class, Culture and Command in the Spanish Army of Flanders, 1567-1659, (Leiden-Boston: Brill, 2009).

Herrero Sánchez 2000: Manuel Herrero Sánchez, El acercamiento hispanoneerlandés (1648-1678), (Madrid: CSIC, 2000).

Inglis-Jones 1994: James John Inglis-Jones, "The Battle of the Dunes, 1658: Condé, War and Power Politics", War in History, 1, 3, (1994), pp. 249-277.

Inglis-Jones 1994: James John Inglis-Jones, The Grand Condé in exile: Power Politics in France, Spain and the Spanish Netherlands. 1652-1659, (Tesis Doctoral, Universidad de Oxford, 1994).

Junot y Kervyn 2015: Yves Junot y Marie Kervyn, "Los Países Bajos como tierra de recepción de exiliados", en Los exiliados del rey de España, coord. José Javier Ruiz Ibáñez e Igor Pérez Tostado, (Madrid: Fondo de Cultura Económica, 2015), pp. 207-231.

Keay 2008: Anna Keay, The Magnificent Monarch. Charles II and the Ceremonies of Power, (Londres, Nueva York: Bloomsbury Continuum, 2008).

Leestmans 2003: Charles J. A. Leestmans, Charles IV, duc de Lorraine (16041675). Une errance baroque, (Lasne: Par Quatre Chemins, 2003).

Lefèvre 1924: Joseph Lefèvre, "Le Ministère Espagnol de I'Archiduc Albert 1598-1621", Bulletin de l'Académie Royale de Archéologie de Belgique, 1, (1924), pp. 202-224.

Lenders 1990: Piet Lenders, "Services d'assistance et de contrôle auprès des Gouverneurs des Pays-Bas Méridionaux (XVIIe-XVIIIe siècle)", Archives et Bibliothèques de Belgique 61, 3/4, (1990), pp. 447-468.

Lenders 1995: Piet Lenders, "Secrétairerie d'État et de Guerre", en Les Institutions du Gouvernement Central des Pays-Bas Habsbourgeois (14821795), ed. E. Aerts et al., vol. 1, (Bruselas: Archives Générales du Royaume, 1995), pp. 383-395.

Lenet 1838: Pierre Lenet, Mémoires, ed. Michaud y Poujoulat, (París: Chez l'éditeur du Commentaire Analytique du Code Civil, 1838).

Lonchay 1933: Henri Lonchay et al. (ed.), Correspondance de la cour d'Espagne sur les affaires des Pays-Bas au XVIIe siècle, vol. 4, (Bruselas: Maurie Lamertin, 1933).

Maffi 2014: Davide Maffi, En defensa del Imperio. Los ejércitos de Felipe IV y la guerra por la hegemonía europea (1635-1659), (Madrid: Actas, 2014).

Malcolm 2017: Alistair Malcolm, Royal Favouritism and the Governing Elite of the Spanish Monarchy 1640-1665, (Oxford: Oxford University Press, 2017). 
Malo 1937: Henri Malo, Le Grand Condé, (París: Tallandier, 1937).

Marcos Martín 2001: Alberto Marcos Martín, "España y Flandes (1618-1648): la financiación de la guerra", en Calderón de la Barca y la España del Barroco, ed. José Alcalá-Zamora y Ernest Belenguer, vol. 2, (Madrid: Centro de Estudios Políticos e Institucionales, 2001), pp. 15-39.

Martínez Peñas 2009: Leandro Martínez Peñas, El confesor del rey en el Antiguo Régimen, (Madrid: Editorial Complutense, 2009).

Negredo del Cerro 2005: Fernando Negredo del Cerro, Los predicadores de Felipe IV. Corte, intrigas y religión en la España del siglo de oro, (Madrid: Actas, 2005).

Oliván Santaliestra 2006: Laura Oliván Santaliestra, Mariana de Austria. Imagen, poder y diplomacia de una reina cortesana, (Madrid: Editorial Complutense, 2006).

Parker 1985: Geoffrey Parker, El ejército de Flandes y el Camino Español, 1567-1659, (Madrid: Alianza Editorial, 1985).

Pujo 1995: Bernard Pujo, Le Grand Condé, (París: Albin Michel, 1995).

Ruiz Rodríguez 2007: Ignacio Ruiz Rodríguez, Don Juan José de Austria en la Monarquía Hispánica: entre la política, el poder y la intriga, (Madrid: Dykinson, 2007).

Sáenz Berceo 2014: María del Carmen Sáenz Berceo, Confesionario y poder en la España del siglo XVII: Juan Everardo Nithard, (Logroño: Universidad de La Rioja, 2014).

Scott 1907: Eva Scott, The Travels of the King: King Charles II in Germany and Flanders 1654-1660, (Londres: Archibald Constable and Company, 1907).

Séré 2007: Daniel Séré, La Paix des Pyrénées. Vingt-quatre ans de négociations entre la France et l'Espagne (1635-1659), (Paris: Honoré Champion, 2007).

Thiéry 2009: Hélène Thiéry, "À la découverte d'un acteur de la Fronde à Bordeaux: la mission du baron de Vatteville (1649-1653)", Annales du Midi, 121, 265, (2009), pp. 37-56.

Valladares 2009: Rafael Valladares, "Haro sin Mazarino. España y el fin del 'orden de los Pirineos' en 1661", Pedralbes, 29, (2009), pp. 371-372.

Valladares 2016: Rafael Valladares (ed.), El mundo de un valido. Don Luis de Haro y su entorno, 1643-1661, (Madrid: Marcial Pons, 2016).

Vermeir 2002: René Vermeir, "En el centro de la periferia: los Gobernadores Generales de Flandes, 1621-1648", en España y las 17 provincias de los 
Países Bajos: una revisión historiográfica (XVI-XVIII), coord. Ana Crespo Solana y Manuel Herrero Sánchez, vol. 1, (Córdoba: Universidad de Córdoba, 2002), pp. 387-402.

Vermeir 2006: René Vermeir, En estado de guerra. Felipe IV y Flandes, 16291648, (Córdoba: Universidad de Córdoba, 2006).

Vermeir 2008: René Vermeir, "Les limites de la monarchie composée: Pierre Roose, factotum du comte-duc d'Olivares aux Pays-Bas espagnols", DixSeptième siècle, 240, (2008), pp. 495-518.

Vermeir 2010: René Vermeir, "Charles IV de Lorraine et I'Espagne 16341659", Hémecht. Revue d'histoire luxembourgeoise, 62, (2010), pp. 393402.

Vermeir 2011: René Vermeir, "Un austriaco en Flandes. El archiduque Leopoldo Guillermo, Gobernador General de los Países Bajos meridionales (1647-1656)", en La dinastía de los Austria: las relaciones entre la Monarquía Católica y el Imperio, coord. José Martínez Millán y Rubén González Cuerva, vol. 1, (Madrid: Polifemo, 2011), pp. 583-608.

Vermeir 2014: René Vermeir, "Les Gouverneurs-Généraux aux Pays-Bas Habsbourgeois", en À la place du roi. Vice-rois, Gouverneurs et ambassadeurs dans les monarchies française et espagnole (XVIe-XVIIIe siècles), coord. Daniel Aznar, Guillaume Hanotin y Niels F. May, (Madrid: Casa de Velázquez, 2014), pp. 17-34. 